Florida International University FIU Digital Commons

3-28-1996

\title{
Achievement motivation attributes of international students attending a postsecondary institution
}

Paula Chernoff Epstein

Florida International University

DOI: $10.25148 /$ etd.FI15101302

Follow this and additional works at: https://digitalcommons.fiu.edu/etd

Part of the Adult and Continuing Education Commons, and the International and Comparative Education Commons

\section{Recommended Citation}

Epstein, Paula Chernoff, "Achievement motivation attributes of international students attending a postsecondary institution" (1996). FIU Electronic Theses and Dissertations. 3145.

https://digitalcommons.fiu.edu/etd/3145 


\section{FLORIDA INTERNATIONAL UNIVERSITY}

Miami, Florida

\section{ACHIEVEMENT MOTIVATION ATTRIBUTES OF INTERNATIONAL STUDENTS ATTENDING A POSTSECONDARY INSTITUTION}

A dissertation submitted in partial satisfaction of the requirements for the degree of

DOCTOR OF EDUCATION

IN

ADULT EDUCATION/HUMAN RESOURCE DEVELOPMENT

by

Paula Chernoff Epstein

1996 


\section{DISSERTATION COMMITTEE APPROVAL SHEET}

TO: Dr. Ira Goldenberg

College of Education

This dissertation, written by Paula Chernoff Epstein, and entitled Achievement Motivation Attributes of International Students Attending a Postsecondary Institution, having been approved in respect to style and intellectual content, is referred to you for judgement.

We have read the dissertation and recommend that it be approved.

Dr. Paulette Johnson

Dr. Jetirro Toomer

Dr. Douglas Smith, Major Professor

Date of Defense: March 28, 1996

The dissertation of Paula Chernoff Epstein is approved.

Dr. Ira Goldenberg

Dean, College of Education

Dr. Richard Campbell

Dean of Graduate studies

Florida International University, 1996 
ACKNOWLEDGEMENTS

Hard to believe that I can now join the rest of the Epstein family, my daughter Sandra - Doctor of Jurisprudence, my son Jason - Doctor of Jurisprudence, and their father Michael - Doctor of Philosophy in Psychology, as a Doctor of Education. I want to thank them for their encouragement and for their patience during this long process. In addition, a special thanks to my mother and brother for "pushing" me along to finish.

I also want to express my sincere gratitude to my friends and staff at Miami-Dade Community College and to my friends outside of work for all the help and support they so graciously gave to me to make this dissertation a reality.

To all my professors at FIU, especially my committee members Drs. Doug Smith, Paulette Johnson and Jeff Toomer, I give my heartfelt thanks for your knowledge which you willingly shared with me and for your understanding in "putting up" with me. 


\section{ABSTRACT}

Achievement Motivation Attributes of International students Attending a Postsecondary Institution

by

Paula Chernoff Epstein

Florida International University, 1996

Professor Douglas Smith, Major Professor

The purpose of this study was to identify and compared the causal attributes of achievement motivation for academic success possessed by international students to those causal attributes of achievement motivation by other legal immigrant student groups attending a postsecondary institution. In this study, F-1 international students have obtained permission from the federal Department of Immigration and Naturalization Services to attend Miami-Dade Community College in Miami, Florida. There were two additional groups of students selected to participate in this study: Permanent Resident students and Others comprised of asylees, refugees and paroles, which are specific categories of legal immigrant students.

From the observations of the investigator, international students were more successful at the institution as compared to the other two student groups as measured by such 
variables as Grade Point Average, Number of Credits Earned and Honors Day awards. By identifying these attributes of achievement motivation, additional curricula, support services and activities can be developed to meet the needs of these highly motivated students.

Incorporating the theories of McClelland and Weiner in the theoretical framework of the study, both quantitative and qualitative data were collected from 150 subjects using the Measurement of Achievement Motivation Questionnaire and the Guided Biography Interview as data collection instruments. Statistical analyses on the data collected from the three groups of foreign born students at the institution indicated differences in these identified attributes and their effects on academic success.

Results indicated that F-I international students at Miami-Dade Community College were highly motivated to achieve, possessed different causal attributes of achievement motivation and displayed their need for achievement in different activities and in different ways as compared to the Permanent Resident and Other student groups. Further investigation on the importance of residency status as an influencing factor of achievement motivation is suggested. 


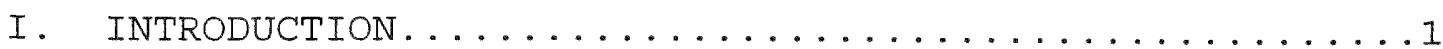

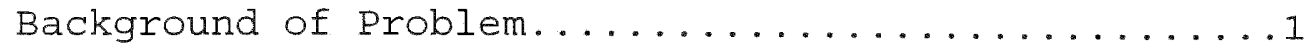

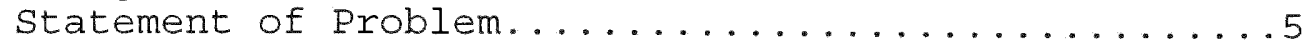

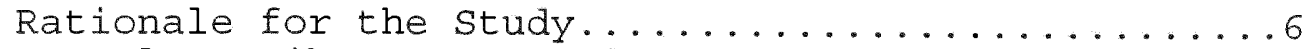

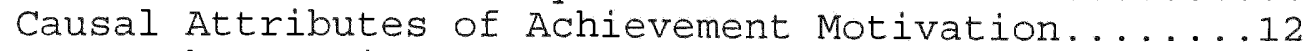

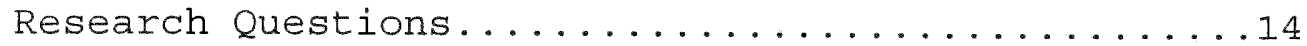

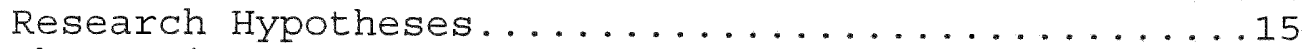

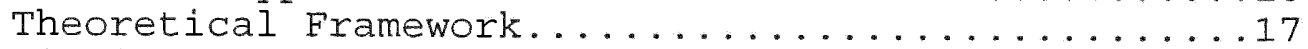

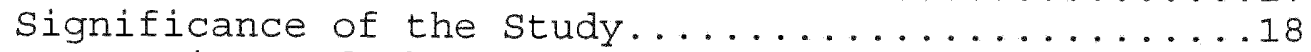

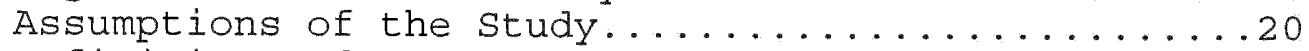

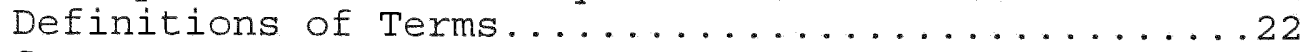

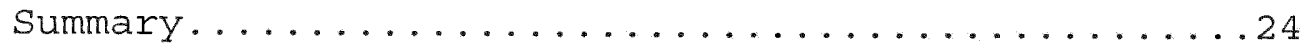

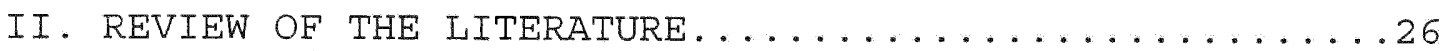

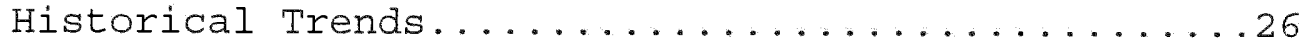

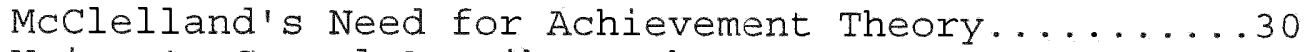

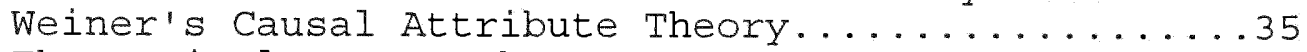

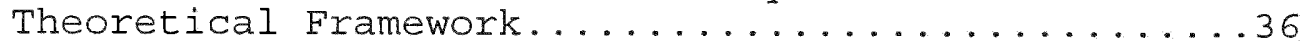

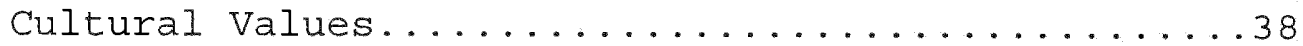

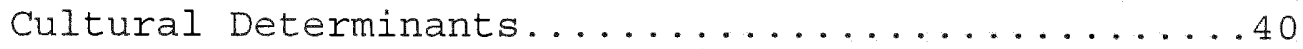

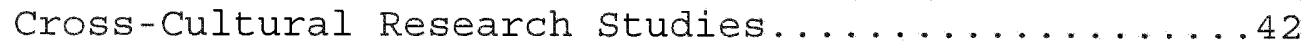

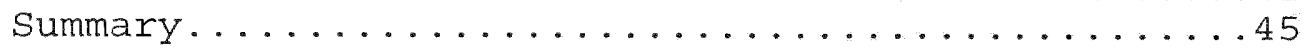

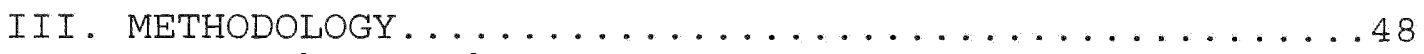

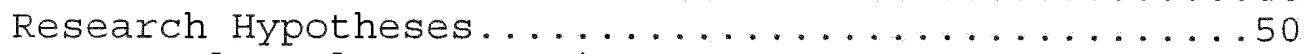

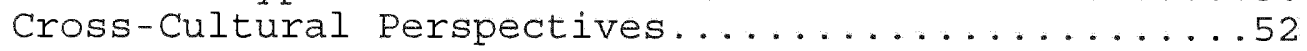

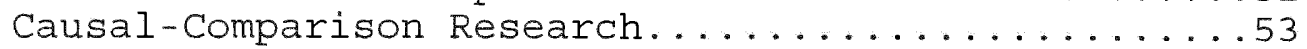

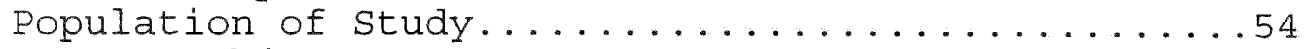

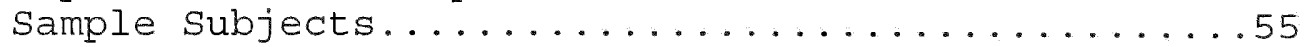

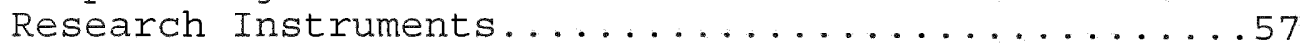

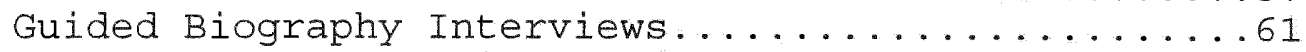

Validity and Reliability of the Instruments......64

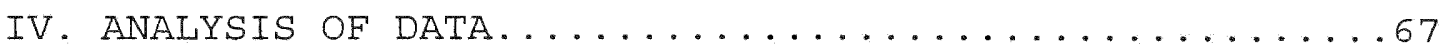

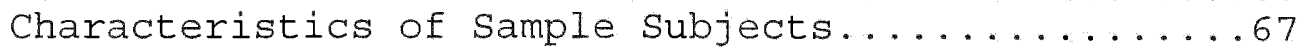

Measurement of Achievement Motivation Results.....75

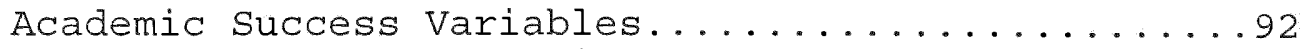

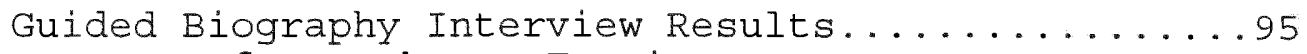

Summary of Hypotheses Testing.................. 104

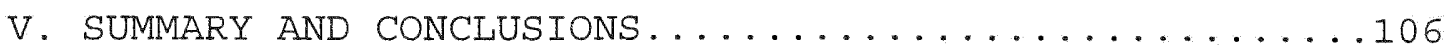

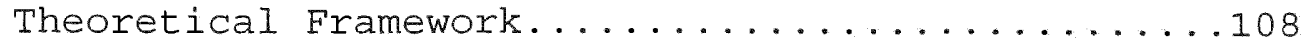

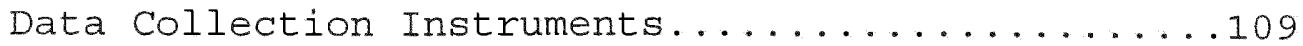

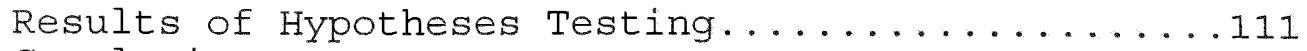

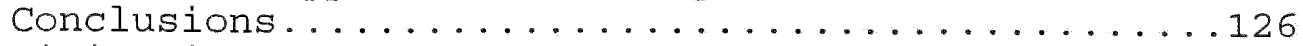

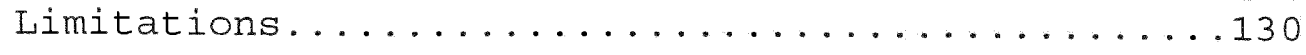




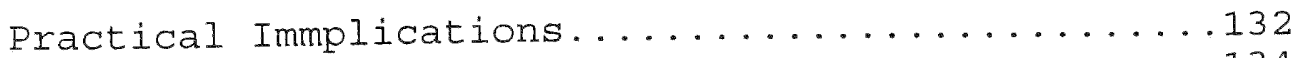

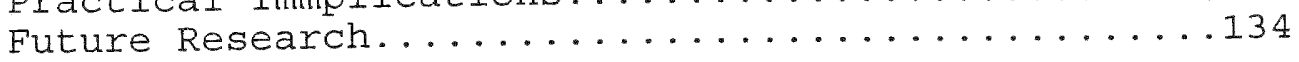

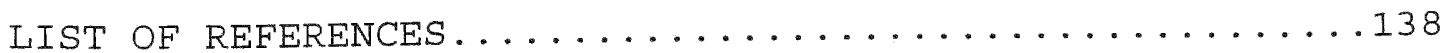

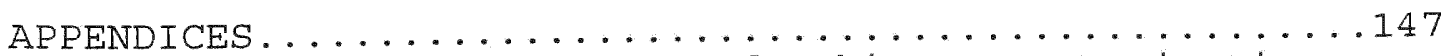

Appendix A Measurement of Achievement Motivation

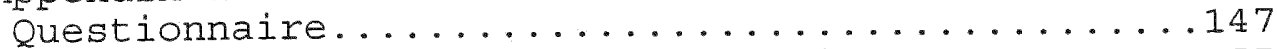

Appendix B Guided Biography Interview.........................

Appendix C Distribution of Countries............160 


\section{LIST OF TABLES}

TABLE

PAGE

1 Distribution of Age by Residency Status......70

2 One Way Analysis of Variance on Age by

Residency Status..................71

Distribution of Geographic Areas by Residency

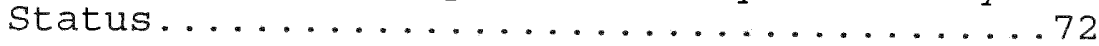

4

Distribution of Number of Semesters at MiamiDade Community College by Residency

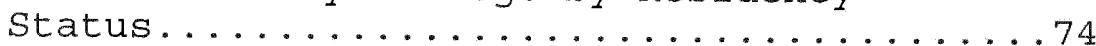

5 One Way Analysis of Variance on Number of

Semesters at Miami-Dade Community College

by Residency status..................74

6 One Way Analysis of Variance on Task Orienta-

tion Scores by Residency Status.........78

7 One Way Analysis of Variance on Perseverance Scores by Residency status............79

8 One Way Analysis of Variance on Parental

Affection Scores by Residency Status......80

One Way Analysis of Variance on Fear of Failure Scores by Residency Status.......81

10 One Way Analysis of Variance on Social

Acceptance Scores by Residency status.....82

11. One Way Analysis of Variance on Success/

Failure Mean Scores by Residency Status...83

12 One Way Analysis of Variance on Future orien-

tation scores by Residency status.......83

13 One Way Analysis of Variance on Involvement Scores by Residency Status............84

14 One Way Analysis of Variance on Parental Restrictiveness Scores by Residency Status...85

15 One Way Analysis of Variance on Testtaking Scores by Residency status...........86

16 One Way Analysis of Variance on Competitiveness Scores by Residency status........87 
One Way Analysis of Variance on Independence Scores by Residency status............88

18 One Way Analysis of Variance on Rigidity Scores by Residency Status............89

19 One Way Analysis of Variance on Unidentified Scores by Residency Status.............90

20 One Way Analysis of Variance on Anticipatory Scores by Residency status.............91

21 One Way Analysis of Variance on Grade Point Averages by Residency Status...........93

22 One Way Analysis of Variance on Cumulative Credits Earned by Residency Status........94

23 One Way Analysis of Variance on Number of Credits Registered by Residency Status....994

24 One Way Analysis of Variance on Number of Changes in Majors by Residency Status.....95 
CHAPTER ONE: INTRODUCTION

This chapter provides the background information for this study's research on the causal achievement motivation attributes for academic success by international students enrolled at an urban community college. The historical trends of international students' enrollment at postsecondary institutions in the United States are presented. An overview of the services provided by postsecondary institutions for international students is then reported. This chapter concludes with a summary of the research problem to be addressed by this study.

Background of the Problem

This study identified and compared the causal attributes of achievement motivation for academic success of F-1 international visa students to other foreign born students who have obtained residency status in the United States. The F-1 international students have obtained permission from the United States Department of Immigration and Naturalization Services to attend an educational institution in the United states on a full-time basis. In this study, F-1 international students have selected to attend Miami-Dade Community College, a two year postsecondary institution located in Miami, Florida, which offers both Associate of Arts and Associate of Science degrees. 
Previous research studies on achievement motivation have focused on such subgroups as blacks, gifted children, under-achievers, and migrant workers (Portes \& Wilson, 1976; Astin, 1982; Lay \& Wakstein, 1985). Only recently has attention been directed to the increasing number of foreign students attending postsecondary educational institutions in the United States.

By identifying the characteristics and attributes international F-1 visa students possess in striving for academic success and comparing these attributes to those of other legal immigrant student groups on campus, a profile of a successfully achieving academic student may emerge. A study of international students and their attributes for academic success could contribute to the research literature on motivation and, as a result, lead to further research on educational instruction modalities, course curricula, and support services provided for international students in postsecondary institutions as well as for other groups of students.

Most often the topic of international students, or foreign students as the two terms are often used interchangeably, has been studied extensively from the viewpoint of bilingual education (Maehr, 1974; Mangan, 1991). In most studies, this foreign born population was comprised of young elementary through high school aged students, who having left their home countries for a variety of reasons, enrolled 
in a public or private educational setting in the United States.

Over the last four decades, there has been a continued increase in the number of international F-1 visa students attending colleges and universities in the United states (Moriat, 1990; De Palma, 1990; Smolowe, 1992). Due to this increase, research studies are now addressing the unique characteristics of international students who have chosen to attend a postsecondary educational institution in the United States for advanced academic and/or technical degrees (Mauch, 1984; Maehr \& Braskamp, 1986).

The impetus for the increase in enroliment of international students can be traced back to World War II when many institutions of higher education in Europe were either closed or damaged. Foreign students looked to the United States as a place for obtaining a degree. In addition, after the war the United States initiated educational programs in the countries of Austria, Germany, Korea and Japan as well as recruitment activities to bring students from these countries to the United States for advanced study (Du Bois, 1956).

This influx of international $F-1$ visa students to the United States has continued to the present. Over the last five years international student enrollment has increased by 19\% with 407,530 international students enrolled in the United States' postsecondary institutions for the academic 
school year 1990-91 (American Council on Education, January 20, 1992, p. 3). By 1992-93, there was another increase in international visa student enrollment of $4.5 \%$ with 438,618 international students attending postsecondary institutions (Desruisseaux, 1993). Almost 40\% of all international students are majoring in business or engineering (American Council on Education, 1991, November 4; Baldwin, 1991).

One reason for this increase in international student enrollment is the availability of airplane travel which has made it easier for foreign students to attend educational institutions outside of their home countries. A second reason is the importance of knowing English as well as understanding the American culture which has become an attraction for many international students to come to the United states for postsecondary study. Thirdly, earned degrees from American colleges and universities lead to employment opportunities in the students' home countries or in other locales, and bring added prestige for the students (Carter \& Sedlacek, 1986).

By far, most F-I visa students select four year colleges and universities (87\%) with $13 \%$ attending two year colleges. Though most international visa students select four year institutions, there presently are 60,000 international students attending community colleges (Fersh \& Furlow, 1993). There has been an increase in visa student enrollment at two year colleges in the past few years due to 
the availability of both academic and technical training programs provided at such institutions. In addition, two year colleges usually have lower tuition costs. Foreign students needing English language courses many times take advantage of this cost factor to study English at two year colleges, and then transfer to four year institutions to complete their degrees (Roberston \& Vitales, 1986).

\section{Statement of the Problem}

In this study, the academic performance of international F-1 visa students who have chosen to study in the United states at Miami-Dade Community College in Miami, Florida was analyzed. The achievement motivation factors for their academic performance were identified. Three groups of students were studied: international F-1 visa students and foreign born immigrant students comprised of Permanent Resident students and Others such as refugees, asylees and parolees. Foreign born immigrant students are those students who have obtained legal immigration residency statuses, signifying they are eligible to remain in the United states. Their academic performance was compared to the international F-1 visa students who are required to leave the United States at the end of their programs of study. The importance of identifying achievement motivation attributes for academic success between these three groups may result in a broader understanding of cultural differences among foreign students and the possible need for 
programmatic modifications in instructional techniques and materials to meet these students' needs for academic

success.

Rationale for the Study

Information is currently provided through immediate computerized retrieval systems and advanced technology which will be carried forth into the 21st century. A highly educated populace is required to meet this need for the economic development of countries worldwide including the United States. As Kotkin (1993) states, foreign born engineers who have been educated in the United States and then employed here provide important contributions to our economy in the areas of computer technology, telecommunication systems, and industrial/medical instrumentation fields.

However, the media has continually highlighted the plight of the American educational system in preparing students for the current labor force. Many American students who graduate from high school are still lacking the basic skills in reading, writing and mathematics. However, this is not necessarily the case for those foreign students who earn their degrees in the United States, and either obtain employment here or return back home for better work opportunities (Bracey, 1991; Kirst, 1991). For America to be competitive with other industrial nations, it must have workers who meet minimal educational requirements for 
employment and should not rely on internationals to fill this need.

Lee (1992), in an opposing viewpoint, suggests that it is to the benefit of the United States to increase the number of international visa students coming here to study because only $50 \%$ of them return home after graduation. The others are quickly absorbed into the labor force in the areas of scientific technology which helps keep the United States in the forefront of these industries. Educationally underprepared United States citizens will find themselves competing for job opportunities with more qualified foreign student graduates.

The educational systems and the emphasis placed on academic achievement for students varies throughout the world. In many developed countries, the educational system is far superior to that of the United States (Kirst, 1991; 1993). The curricula are more comprehensive, the course requirements are more extensive and the length of the school year is longer. Japanese students for example attend school six days a week with a very short summer vacation. According to Wade (1990):

Rigid social stratification based on educational achievement, is what gives Japanese students the drive to study feverishly. Their fates in life begin to be determined from their early school years by the quality of the high school and the 
university to which they gain entry. (p. 16)

This perseverance for academic achievement is displayed in the number of international students studying for advanced degrees in the United States. In 1990-91, 45\% of all international students were enrolled in graduate programs. Half of all doctorates in engineering are earned by non-United States citizens, most being from Asia and India (Aviation Week \& Space Technology, 1988, p. 42). In fact, the number of Ph.D.'s earned by American citizens decreased by $9 \%$ while the number of such degrees awarded to non-United States citizens increased by almost 50\% during the years of 1979 and 1989 as reported by the National Research Council (American Council on Education, October 21, 1991, p. 3).

This increasing trend for international visa students to receive more advanced degrees from American colleges and universities has been labeled as the "brain drain" by researchers and educators, meaning that highly skilled and talented students will come from foreign countries and most likely go back to their home countries after graduation, leaving a dearth of qualified professionals in the United States (Lee, 1991; Smolowe, 1992; Levine, Mackinnon \& Reichlin, 1992; Kotkin, 1993).

Even though international student enrollment is increasing, it is not an easy decision for a foreign student to make in deciding to come to the United states for study. 
Since international students may face a myriad of problems or barriers to overcome when leaving their homelands for a strange new country, such as the United states, it must take a strong will and determination to succeed in obtaining an educational degree. Changes in language, food, attitudes, and social interactions are but a few new hurdles international students may encounter upon arriving in the United States (Smolowe, 1992; Mohr, 1994). Hodgkin (1961) states, In any educational experience, motivation or incentive is a key factor in relation to success or failure. Young persons who are sent from home to study need strong motivation to withstand the strain of changes in cultural behavior, of loneliness, and lack of primary group support as well as difficulties of language and new study procedures. (p. 43) Accompanying this increase in the number of foreign students coming to study in the United States is the need for improved support services on college campuses for this specialized body of students to help them become acclimated to life in the United States (Boyer \& Sedlacek, 1989; Dodge, 1990). Mauch (1984) suggests that institutions enrolling a large foreign student population should teach courses on ethnic, linguistic, and religious diversity to the general student population, as well as to provide orientation workshops for foreign students to increase their awareness of college life, the new host culture, and work experiences 
they may encounter upon returning to their home countries. Miami-Dade Community College (MDCC) provides such support services to foreign students. MDCC is a state supported two year community college with five major campuses and several outreach centers located throughout Dade County in Southeast Florida. The statistical breakdown of the 1994-95 credit student body at Miami-Dade Community College is as follows: $33.5 \%$ of the students are between the ages of 21-25 years of age, over $60 \%$ of the student enrollment attend on a part-time basis, the female/male ratio percentage is $58 \%$ female to $42 \%$ male (MDCC Facts in Brief, 1995).

Miami-Dade Community College, the top community college nationwide as reported in a 1985 investigative study conducted by the University of Texas (Roueche, Baker \& Roueche, 1985), has been in the forefront of accepting and assisting foreign students. In the January 1990 Miami-Dade Community College publication, Headlines, the international student enrollment was reported at 5,080 students at the institution which comprises $11.2 \%$ of the college's total enrollment. In interpreting this report, it is important to note that the population included under the term "international" students are all students who are non-United states citizens, nor permanent residents.

The international student population at Miami-Dade Community College can be further subdivided into five 
distinct classifications based on immigration residency status (Baldwin, 1988; 1991): visa students (individuals who have obtained a F-1 visa for study purposes only); resident aliens (permanent residents of the United States); refugees (persons who entered the United States due to persecution in their home country); asylees (individuals who applied for emigration); and parolees (alien category for those not eligible to be classified in the previous categories). For the F-1 visa students who have chosen to study at MDCC, the percentage is $43 \%$ of the total 5,080 foreign students. These two groups of students, F-1 visa international students, and the other foreign immigrant students classified as permanent residents, refugees, asylees and parolees are the focus of this study.

Though ranked number one nationally with the largest postsecondary foreign student enroliment for the sixth year in a row as reported by the Miami Herald (1991, October 16), MDCC's foreign student population profile is quite different from that of other institutions throughout the country. As reported by the American Council on Education (1990), there is at present $52 \%$ of foreign students from Asia, with most coming from China, Taiwan, Japan, India and Korea. At Miami-Dade Community College, as reported by Baldwin (1988), the greatest numbers of foreign students come from the Caribbean Islands, Central American and northern South America. Over 1,600 students, $87 \%$ of the total inter- 
national visa student enrollment, is comprised of students from Latin America (Baldwin, 1991).

With such a large international visa student enrollment, and with a total of 137 different countries represented by that student enrollment, several internal MDCC studies and research reports have been generated on this population. Baldwin (1988) reports that visa students had, on the average, more credit hours attempted and earned than all other groups of the Miami-Dade Community College's student body. The breakdown for degrees was $73 \% \mathrm{~F}-1$ visa students declared themselves to be seeking an Associate of Arts degree, whereas $28 \%$ of the refugees and $26 \%$ of the resident aliens reported to be following the Associate of Science track.

Therefore, one reason for the differences between the various groups of students may be accounted for by differences in the level and type of achievement motivation attributes, causal attributes, they ascribe to their academic performance and future success. It was the intent of this study to investigate these achievement motivation attributes for academic success among the international visa students.

Causal Attributes of Achievement Motivation Over the last three decades, the theories of achievement motivation have moved away from focusing on the internal drives or motives of the individual to account for 
achievement motivation to that of the individual's perception and interpretation of the causes for success or failure at a specific task or in a specific situation. In the 1950's and 60's, McClelland and others proposed that achievement motivation was determined by the internal motives of the individual; the need to achieve, the need to affiliate, and the need for power. McClelland based his theory on subjects' responses to the Thematic Apperception Test (TAT), a projective measurement instrument, to identify achievement motivation characteristics and activities in the stories produced by subjects viewing these TAT cards (MCClelland, 1975).

In a causal attributional approach to achievement motivation, the researcher investigates the perceived causes and reasons for success or failure of a task by questioning the subject through the use of a test instrument and/or interview. Weiner (1974), a theorist most closely associated with causal attributional theory of achievement motivation, states that individuals are more likely to describe and explain the reasons why they continue or discontinue a task than to be able to analyze their internal motives for choosing or completing a task (Weiner, 1985).

The most commonly identified causes for success or failure are ability, effort, luck and task difficulty (Weiner, 1974; 1985). Ability and effort are internal variables pertaining to the individual whereas luck and task 
difficulty are external variables specific to the task, situation and time period. In addition to the dimension of locus (internal and external), two other dimensions, stability and controllability, affect achievement motivation outcomes. Additional information on causal attribution theory is found in Chapter 2, Review of the Literature.

\section{Research Questions}

Since several internal MDCC reports indicated that international F-I visa students are academically more successful than other groups of students and from the investigator's observations as Director of International Students on campus that proportionately to the student body, there were consistently more international F-1 visa students in the campus' honor societies, the basic research question arose as to why F-I international students were so motivated to achieve. This basic research question was further refined into the following five specific research questions: 1. Do visa students differ from other foreign born students on identified causal attributes of achievement motivation for their success in college?

2. Do these causal attributes manifest themselves in higher academic success for F-1 visa students?

3. Does residency classification (international student, permanent resident, parolee) affect a change in achievement motivation factors?

4. Does acculturation into the American society and its 
accompanying values influence academic goals among international students?

5. Are there cultural differences in the importance of education and the techniques in instilling such values in children?

Research Hypotheses

In order to investigate the five research questions, the following supporting research hypotheses were proposed for testing.

In response to the question, "Do visa students differ from other foreign born students on identified causal attributes of achievement motivation for their success in college?", two research hypotheses were posited.

$\underline{H}_{1}$. F-l international students will identify different causal attributes, internal dimensions of ability and effort, as perceived causes for their success as compared to those attributes identified by other foreign born students as measured by a testing instrument.

$\underline{H}_{2} \cdot$ F-I international students will identify different causal attributes, internal dimensions of ability and effort as perceived causes for their success as compared to those attributes identified by other foreign born students as described in narrative form through the Guided Biography Interview.

To research the question, "Do these causal attributes manifest themselves in higher academic success for visa 
students?", three hypotheses were tested.

$\underline{\mathrm{H}}_{3}$. International visa students achieve higher grade point averages than other foreign born students.

$\underline{\mathrm{H}}_{4}$. International visa students complete more credit hours earned than other foreign born students.

$\mathrm{H}_{5}$. International visa students have fewer changes in majors than other foreign born students.

To answer the question, "Does residency classification (international student, permanent resident, parolee) affect a change in achievement motivation factors?", this hypothesis was asked.

$\underline{H}_{6}$. International students identify the need to succeed in college in the United States since they will be leaving after completion of their studies significantly more often than other foreign born students as measured by responses to the Guided Biography Interview.

In response to the question, "Does acculturation into the American society and its accompanying values influence academic goals among international students?", this hypothesis was proposed.

$\underline{\mathrm{H}}_{7} \cdot \mathrm{F}-1$ international students maintain stronger cultural identities as compared to other foreign born students as measured by the responses to the Guided Biography Interview.

To answer the question, "Are there cultural differences in the importance of education and the techniques in 
instilling such values in children?", the following two research hypotheses were asked.

H$_{8}$. Achievement motivation attributes differ among countries as measured by subjects' responses on the testing instrument and responses to the Guided Biography Interview.

$\underline{H}_{9}$. Achievement motivation attributes within a country differ by gender as measured by achievement variables as Grade Point Averages and responses on the testing instrument.

\section{Theoretical Framework.}

The theoretical framework for this research study on the construct of achievement motivation was founded upon the works of David MCClelland and Bernard Weiner. As described in Chapter Two, Review of the Literature, McClelland (1975) identifies achievement motivation as a fundamental internal phenomenon of the individual which can be explored through descriptive storytelling activities using the Thematic Apperception Test (TAT). Weiner (1974; 1985; 1990), however, posits that achievement motivation can be identified through external activities and descriptive personal attributes placed upon the outcomes of these activities among four factors: ability, effort, task difficulty and luck.

For this investigator, achievement motivation is a combination of internal and external factors which are utilized in a variety of specific situations and activities. 
Thus the theories of McClelland and Weiner individually do not account for a complete theory for studying achievement motivation as viewed by this investigator. Therefore, this study combined elements of both Mcclelland and Weiner into a broader concept of achievement motivation and tested this theory by using an instrument, Measurement of Achievement Motivation by John Ory and John Poggio (1975), which has as its theoretical framework, an integration of both theories of McClelland and Weiner.

In addition, descriptive ethnographic information was gathered from individual interviews with selected sample subjects based on Levinson's (1978) Guided Biography Interview techniques.

\section{Significance of the study}

Several reasons can be given as to why a study of the attributes for achievement motivation among F-I international students should be conducted, and what benefits could be derived from such research. First, it is important to understand the dynamics of the educational experience for these international students so as to provide them with the maximum course curricula and opportunities to utilize the skills they already bring to the learning environment. second, by identifying the various factors which contribute to achievement motivation in international students, it may be possible to nurture and develop these attributes in other groups of students and, thus, improve their own degree of 
academic success. In turn, Miami-Dade Community College and other urban postsecondary institutions could benefit from identifying and incorporating similar types of experiences and activities into the curricula for its own student population.

Third, from an institutional perspective at Miami-Dade Community College, there is a cost factor assigned to the length of stay in the system a student incurs who is not successful with the program of study nor has a definite goal in mind when planning an academic program. For example, students who are not performing well in class may use the various available tutorial centers with no cost to the student but with enormous financial usage of resources by the college. However, the college funds used to support these centers are limited and it is the goal of such centers to help students who are motivated to achieve in their studies so it would be more cost effective to identify those students who are really motivated to succeed before enrolling them into tutorial centers.

Also, due to the current financial cutbacks taking place throughout the state of Florida, Miami-Dade Community College has had, at times, to curtail its enrollment. In the future, should the need arise to only select those students who have the highest probability of completing a program of study at the institution, an international student profile comprising the identified variables for 
academic success could be utilized from the information provided in this research study to select these students. Assumptions of the study

In order to conduct the proposed research study, several assumptions were postulated.

1. Students who have identified themselves as degree seeking students are, in fact, working towards that end. 2. Academic achievement is valued positively whereas academic failure is valued negatively by all students. 3. There are no differences in course materials, instructional techniques nor teacher interactions for international F-1 students and other students.

4. The international student population is represented on the Wolfson Campus of Miami-Dade Community College.

\section{Assumed Limitations}

1. The participant pool for visa students is much smaller than that of other foreign students which may affect the random sampling of subjects.

2. Educational programs and training in foreign countries may vary in quality among countries as well as within the same country and, therefore, should not be compared to each other.

3. Since visa students must show proof of adequate financial resources to be admitted to the institution, currently $\$ 16,000$, they may come from more affluent and educated families. 
4. Acculturation into the American society could be delayed for those students coming from Spanish-speaking or Frenchspeaking countries since both languages are spoken by a large segment of Miami's population and traditional customs of those countries are still practiced in specific areas of the city and county. Therefore, students can still maintain their traditional lifestyles which they had in their home countries and not necessarily need to acclimate themselves to their new surroundings as quickly as other non-Spanish or non-French speaking international students. 5. Though many variables such as time in the United States, English proficiency, age and gender may be controlled in the sampling procedures other non-identified cultural variables could have a confounding effect on the results of the study. An example of such a variable is child-rearing practices. 6. As stated by Borg and Gall (1983), causal-comparison research studies do not prove cause and effect results and should not be interpreted as such. Since this study is not an experimental design study where variables are controlled and manipulated, other confounding variables not readily identifiable may influence the obtained results. It is, therefore, important not to consider the results of this study as proving or disproving a cause and effect relationship between achievement motivation attributes of international F-1 visa students and academic success. 7. The unique characteristics of the sample population 
which has selected to attend a large community college in a large urban area may differ greatly from that of other groups of international students who have selected smaller community colleges in other areas of the country. It is, therefore, important not to generalize the results of the study to non-urban institutions which may enroll international F-1 students. Definition of Terms

The following listing contains the terms and definitions pertinent to this study.

Achievement motivation. Specified behavior aimed at successful completion or mastery of a task which may include the individual's competition with others or to a standard of excellence in performance (Murray, 1938).

Associate of Arts. Degree designed for transfer to upper division universities after graduation (MDCC Catalog, 1991-92, p. 41).

Associate of Science. Degree programs designed to prepare students for immediated employment after graduation (MDCC Catalog, 1991-92, p. 41).

Asylee. Person already in the United States or port of entry when he applied for emigration (Baldwin, 1988, p. 26). Culture. Complex whole which includes knowledge, belief, art, morals, law, customs, and any other capabilities and habits acquired by man as a member of society (Tylor's study cited in Brameld, 1975, p. 7). 
Multiple Assessment Programs and Services examination (MAPS). Examination consisting of four subtests in reading, writing, basic mathematics and algebra. The scores from this exam are used in placing students into appropriate levels of English and math classes (MDCC Catalog, 1991-92, p. 35).

Parolee. Alien category for other individuals who can not be classified in any designated grouping (Baldwin, 1988, p. 26).

Resident Alien. Permanent resident of the United States, who has the right to financial aid, Social security benefits and social services (Baldwin, 1988, p. 26).

Refugee. Person who was admitted to the United States under the threat of persecution due to race, religion, nationality, membership in a social group or political opinion in his home country (Baldwin, 1988, p. 25).

Test of English as a Foreign Language (TOEFL). English language placement test required for international students from non-English speaking countries (MDCC Catalog, 1991-92, p. 35).

Visa student. Any F-1, full-time foreign student who has met all the qualifications of the Immigration and Naturalization Service and the educational institution to pursue a degree (Baldwin, 1988, p. 25). 


\section{Summary}

This chapter presented the background information for a study of causal attributes of achievement motivation of international F-1 students attending Miami-Dade Community College. From the information provided in this chapter, one may ask the question why are international F-1 students, who are non-United States citizens, motivated to attend postsecondary institutions for advanced degrees while United States citizens appear to be losing their motivation to continue in school? With the forecasted increasing trend for international visa students to come to the United States to study and for more of these students to be earning advanced degrees in very technical fields, it becomes important to identify motivational factors and attributes which may lead to adapting our educational practices to encourage American students to have similar attributes to reach their academic potential as do international students. In addition, students raised and educated in the same country, in general, should possess similar achievement motivation attributes for success. If however, there appears to be a lessening in the level of achievement motivation and aspirations for academic success once the student has a change in immigration residency to allow him to stay in the United States, it would be important to provide ways to enhance the desire for continued academic success in the 
student. In this way, the college could prevent the loss of this valuable asset in our students and, in turn, provide for the future of the community since these students may continue to live and work in the area.

The following chapter reviews the relevant literature on achievement motivation, causal attributes and crosscultural studies. The theories of McClelland and Weiner are highlighted as the basis for this study. 


\section{CHAPTER TWO: REVIEW OF THE LITERATURE}

In this chapter, the theoretical background for this research study is presented. An overview of the historical trends in achievement motivation research is provided. Two major theories, $n$-ach by McClelland and causal attributes by Weiner are described and reviewed, as this research study is based on both theories. The importance of culture as an influencing determinant of achievement motivation is described and pertinent research studies are included.

Review of Theoretical Literature

In order to understand the phenomena of achievement motivation, a brief historical overview of the research on this topic is provided. This overview depicts the theoretical changes the construct of achievement motivation has gone through over time.

\section{Historical Trends in Motivation}

Over the years there has been a trend in the research to move from the physiological nature of motivation to a more psychological, cognitive dimension of motivation. That is not to say that one perspective is better or more accurate than the other, but that there have been different approaches to the research regarding the basis of motivation over time. Early research on the subject of motivation, behaviorism as it was originally called, concluded that an 
individual was instinctively driven to do certain things, to elicit certain behaviors, either from a voluntary or automatic reflex to the present stimuli (Hilgard, 1962). In the 1890's, James expounded that the individual had many more instincts than other animals and that learned experiences over time strengthened and expanded these instincts (Hilgard, 1962; Weiner, 1990).

Most of the research on instinctual drive theory was conducted on animals. Two famous researchers of that time period were Watson and Pavlov. It was Watson who brought experimental psychology into the realm of objectivity, in that what was being seen and recorded was done so with objective measurements. He differentiated the various types of movements as either being explicit or implicit movements. Explicit movements were those easily observed and measured whereas implicit movements were only measured by sensitive instruments (Hall, 1961; Hilgard, 1962).

Following in the tradition of animal research, Pavlov concentrated on the Stimulus-Response Classical Conditioning model which he used in his work with dogs. He studied the origins of conditioned responses by training a dog to salivate to the sound of a bell or ray of light, at first with the reinforcement of meat powder and then later, without such reinforcement. In terms of human actions, it was the anticipation of a reward or reinforcement that elicited appropriate behaviors to gain that specific end 
result as thought by Pavlov (Hilgard, 1962).

Furthering this development in experimental psychology, Tolman developed his theory of trial and error behavior. Insight became a major component of behavior in that an organism considered options or possible solutions and the consequences to an action prior to committing to that action. The physiology of the organism was taken into consideration as were the past learning experiences of the organism. The physiological drives were labeled first order drives whereas second order drives were void of a physiological base and were present due to an outside incentive or goal which was to be met (Hall, 1961).

The concept of conscious and unconscious motivation as a theory was popularized in the 1920's by Freud. A shift was being made from the behaviorists' learning theories of the early part of the century to a more psychodynamic orientation to behavior (Weiner, 1990). There are three major elements that guide behavior according to Freud's theory, the $i d$, ego and superego. The id is most primitive in nature, based on pure instinct and in need of immediate gratification. The ego is the controlling mechanism of the being. It is able to keep the individual in guard for delayed gratification of needs. The superego is most often associated with the "societal conscience" of the individual and maintains an "ideal" for which the individual must strive. The individual is driven by the unconscious to 
perform and is controlled by the interactions of the id, ego and superego (Hall, 1961; Hilgard, 1962).

As research continued into the 1930 's, a new theory emerged that focused on the current status of the individual and not on the past history of the person to explain behavior. This theory was known as Field Theory and was most closely associated with Lewin and then Atkinson (Atkinson, 1964). The individual's environment or lifespace and the external forces acting upon the individual cause the development of personality to differentiate itself into regions within the whole. Due to the effects of these external forces, the individual reacts in such a manner to satisfy its present need, to alleviate the force, and, in specific circumstances, to complete the task at hand. The theories of both Tolman and Lewin were cognitive orientations to the research on learning and motivation. These theories were also known as Expectancy Times Value models of behavior (Atkinson, 1964; Atkinson \& Birch, 1970).

In the 1950's with the theories of humanistic psychology most popularized by Maslow, psychologists began to identify internal needs or goals in the individual. For example, individuals have a need for safety, for interpersonal relations, for self-actualization as identified needs. This movement abandoned the pathology centered theories of the past decades. Attention was placed on the potential of the individual for growth and maturity and gave 
to the individual choice and responsibility. As important as the specific behaviors one demonstrated in a situation were the feelings one had about that action.

The identification of the psychological side of the individual also had a cultural component as well which determined the individual's motivation to act. In fact, different cultures have different ways of fostering and instilling values and methods of achieving satisfaction of a need or goal. The individual within that society takes on a dual role in that he strives to meet his own needs and those of his culture at the same time. Benedict (Goble, 1970, p. 261) states,"...societies have social orders in which the individual, by the same act and at the same time, serves one's own advantage and that of the group." Therefore, it is important to understand the significance of culture on the motivational factors of the populace and the activities in which they engage.

McClelland's Need for Achievement Theory n-ach

McClelland's theory of motivation is based on three major components or needs: the need for achievement, the need for affiliation, and the need for power (McClelland, 1951, 1955, 1967). A major research project on motivation was undertaken in the late 1940's by McClelland and Atkinson. In this study, the subjects were army men who had not eaten for one, four or six hours. They were then asked to write imaginative short stories based on Murray's 
Thematic Apperception Test (TAT) pictures. These stories were then scored and the results showed that over time there was no increase in food imagery or food themes in the stories. In addition, there was a decrease in the goal of eating as related in the stories. However, there was a marked increase in the food deprivation plots of the stories over time (McClelland, 1967).

From his research, McClelland described the various traits inherent in individuals to achieve. He further refined his theories to compare these characteristics noting similarities and differences between high and low achievers (McClelland, 1955, 1967). The need for achievement, n-ach, does not necessarily display itself in the activities of designated high achievers more than in designated low achievers. In fact, if the task to be completed is monotonous or boring, there is no challenge for the high achievers to perform well. High achievers like to compete with others in successful mastery or completion of a project. Characteristics of high n-ach individuals include the tendency to establish moderate goals for themselves and to put forth greater effort when the chance for success is only moderately great (McClelland, 1955; Atkinson, 1957; Atkinson \& Feathers, 1966).

In addition, high achievers prefer to work independently in situations where they can take personal responsibility for their performance instead of in group work. On 
going feedback as to the quality of their work is important to high achievers. They are responsive to criticism. Also, high n-ach individuals show more attention and initiative in utilizing their environment for discovery purposes (McClelland, 1955; Atkinson, 1957; Atkinson \& Feathers 1966).

Veroff, Atkinson, Feld and Gurin (1984, November) conducted a research study on achievement motivation among various groups of Americans in the 1960's by employing the interview method of data collection. They concluded that Americans with high $\mathrm{n}$-ach had higher levels of education and higher occupational levels than did low $\mathrm{n}$-ach individuals. High n-ach individuals assumed early adulthood responsibilities between the ages of 21 to 24 years of age. High achievers also tended to grow up in complete families where there was neither divorce nor death of a parent before the children turned sixteen years of age.

Supporting research by Winterbottom (1958) has shown a correlation between the onset of age of independence training in children among various cultures and achievement motivation. As McClelland postulated, the age at which independence training begins, the number of related independence experiences provided and the emotional support given to a young child play a big role in fostering achievement motivation in that child. These hypotheses on the relationships of independence training and achievement 
motivation were investigated by McClelland by reviewing folktales of American Indian tribes and from interviews and questionnaires administered by Winterbottom to American family members from the Midwest.

In achievement motivation theory following the model of Murray and McClelland, the individual has internal impetus to excel, to reach a specific standard of excellence which usually involves competition. The individual strives to obtain a desired successful outcome and to avoid failure. For value orientation, the individual pursues organized societal behavior which guides his conduct. In this way it outlines for the individual the positive goals and preferences valued by his environment. Value orientation, therefore, is culturally determined and varies from society to society (Atkinson \& Birch, 1978). Also, McClelland termed this value as "v-ach".

The student, in an educational setting, tends to adhere to parental values for education which the student learned as a child. Middle class children have been encouraged to succeed in school more often than children from lower class families. Parental values toward education, the types of books found in the house, plus activities and educational experiences afforded the child contribute to a positive attitude towards learning. The child grows up striving for academic success.

Rosen states (1985, p. 508) that "given the willingness 
to work hard, plan and make the proper sacrifices, an individual should be able to manipulate his environment so as to ensure eventual success." Rosen explored the psychological and cultural factors which influenced achievement motivation and social mobility. He hypothesized that the differences in social classes in America were associated with different degrees of achievement motivation, the internal need to excel. In addition, the individual's adoption of societal expectations effects social mobility and achievement motivation.

Douvan (1975) also studied the significance of social class in the achievement level of school aged children. Her research supports the conclusions of Rosen's work on the importance of parental values and societal expectations. An interesting finding from her research study indicated that high school students from working class families decreased in achievement when the material reward was absent while the achievement level for middle class students remained the same with or without the reward. Therefore, the importance of instilling values for achievement begins in childhood and is positively correlated with the social class of the parents.

McClelland expanded on the concept of cultural determinants of behavior in his work in The Achieving Society. He proposed that social motivation, that of groups of people in a country, fosters the degree of achievement 
motivation of its citizens. In fact, he states "that those countries that developed a strong motive for achievement in their children reaped economic gains in the years to come as the children developed into entrepreneurs" (1967, p. 105). This cultural value for achievement may be one reason a large percentage of the international visa students at MDCC major in business administration.

Weiner's Causal Attribute Theory of Motivation

Weiner's construct of motivation regards the success or failure at a task as being divided into four elements. Two internal elements include one's own ability and one's effort. The two external elements are difficulty of the task and luck. People identified as high or low achievers differ in their self-regard and in the attributes they ascribe to their successes and failures. In any given situation, the individual must assess his own ability, the effort expended, the difficulty of the task and the element of luck involved in obtaining a successful outcome (Weiner, 1985).

Not only are the four elements, ability, effort, task difficulty and luck, of influence in determing success or failure for the individual, they do not possess the same degree of stability nor control. Therefore, they fluctuate depending upon the specific situation and time period. Whereas ability of the individual is most often a constant component and task difficulty relatively stable, effort may 
change over time due to factors such as fatigue, hunger, and mood. Luck, by its very definition, is highly variable in nature (Weiner, 1985).

Weiner's research has shown that persons high in achievement motivation attribute high ability and high effort to their success. For those persons with low achievement motivation, none of the four elements was clearly chosen as to account for success. Failure at a task, on the other hand, was attributed to lack of ability by those low in achievement motivation and to a lack of effort by those high in achievement motivation.

\section{Review of Empirical Literature}

The review of empirical literature provides supportive material to the theoretical framework for this study on achievement motivation. The basis for this study incorporated the $\mathrm{n}$-ach theory of achievement, the causal attribute theory of achievement motivation and the cultural determinants of achievement motivation.

\section{Theoretical Framework for this study}

The theoretical framework for this research study on achievement motivation for academic success was based on a merger of McClelland's and Weiner's theories of motivation from a cross-cultural perspective. At one time, it would seem to be inconceivable that one could adhere to both theories at the same time since they appear on the surface to be mutually exclusive. However, this is not the case. 
In fact, McClelland over the past few years has expanded his theory of motivation to include a broader regard for the importance of causal attributes of achievement motivation (McClelland, 1989).

In his earlier years of research, McClelland viewed motivation as an intrinsic force in the individual, somewhat like a drive in animals, that was activated by a specific behavior. As previously discussed, he designated the need for achievement as n-ach. Most often, he derived n-ach of individuals from the fantasy stories of the TAT cards they reported to him. However, he noted that individual selfreports on the desire to achieve did not correlate with his analysis of achievement motivation found in the stories of those individuals.

By 1955, deCharms, Morrison, Reitman and McClelland coined the term $\mathrm{v}$-ach, for valuing achievement as that dimension of achievement motivation found in self-reports. Rarely do $\mathrm{n}$-ach and $\mathrm{v}$-ach motives significantly correlate to each other. To explain this strange phenomena, three options were posited by the researchers. First, following the research of Entwistle, Campbell and Fiske, measures of motivation from creative stories were worthless. Second, self-report measures were not designed properly as proposed by Raven. Third, two different types of achievement motivation were being equated while they were, in deed, different but yet, both important in understanding individual be- 
havior.

\section{Cultural Values}

With MDCC's large international student population from over 137 different countries, a study utilizing culture as one variable affecting achievement motivation may provide an explanation to the differences in academic success for the specific groups of students under investigation as based on McClelland's theory. However, to further include additional factors influencing motivation, the inclusion of Weiner's theory of achievement motivation may expand the importance of culture in explaining achievement motivation for international students.

Cultural values and expectations play an important role in the development of achievement motivation attributes for the individual, especially in the internal elements of ability and effort. If the success of an event is dependent upon the internal elements, then the individual feels pride in himself for the successful outcome and shame at the failure of a task. With success, the individual regards himself as supporting his specific reference group and in failure, he views himself as disappointing this group.

of special importance for this study was the specific relationship of achievement motivation in an educational setting and academic success. Conclusions from the research conducted in the mid 1980's (Shavelson and Bolus, 1982; Byrne, 1986) have shown that prior academic success and 
accomplishments determine academic self-concept. If a student experiences positive academic results as shown in grades and teachers' comments, this student will develop a positive self-concept toward education and will work toward academic success.

Hutslar, Litcher and Knight (1985), in their study on junior high school students, support the importance teachers have on influencing the achievement motivation of students as well as past successes. They administered the selfMotivation Inventory (SMI) to a sample of junior high school students as well as developed a teacher rating scale of student motivation from data collected from the students' teachers. Teachers rated student performance in three areas, social behavior/responsibility, readiness to learn, and the ability to learn. There was a positive correlation between a student's score on the SMI with that of the teacher's rating. Also, it was concluded that the differences for students scoring high on the SMI from those scoring low on the instrument were dependent upon class rank (past academic performance) and mother's level of education (child rearing practices).

In this study, the utilization of the Measurement of Achievement Motivation Questionnaire for data collection provide information on culture in influencing an individual's self-described attributes for success based on Weiner's variables of ability, effort, task and luck. 


\section{Cultural Determinants of Achievement Motivation}

McInerney and Sinclair (1991) examined the predictors of achievement motivation for academic success in three cultural groups found in Australia; the aboriginals, anglos, and migrants. Subjects were selected from 12 secondary schools in New South wales and were administered the Inventory of School Motivation (ISM). Using a Likert-type scale, responses to 100 statements covering 11 different dimensions of motivation were tabulated and analyzed. It was concluded that, to varying degrees among the three cultural groups, the dimensions of intrinsic motivation, competition and goal-direction accounted for the students' performance in completing the task.

Lay and Wakstein (1985) employed data from the 1981 administration of the Scholastic Aptitude Test (SAT) and the optional student Description Questionnaire (SDQ) to investigate the differences on achievement between white and black students in the United States who were planning on attending college. This study incorporated the students' scores on the verbal SAT, math SAT, student self-report of high school grades as well as the scores on the SDQ instrument for self-esteem. This information was used to determine the relationship of race, academic achievement and self-concept. One significant finding was that the level of self-esteem among blacks was dependent less on past high 
school academic accomplishments than that of white studu A better predictor for academic success among minority students was the self-esteem score on the SDQ not the SAT verbal and math scores.

Hodgkin, in her study on cross-cultural education in Australia, noted that Chinese students attending universities in Australia faced societal pressures from people in their home countries to succeed in school. "Fear of losing face influences the actions of students who fail in examinations or have to return home without credentials for which they originally came to Australia" (Jenkins, 1983, p. 427). Also, she found that Indian students from southern India and Ceylon were motivated to succeed in their studies in Australia because of the prospect of obtaining better employment opportunities in their home countries upon returning with a degree from Australia. The Malays, Indian students from southeast Asia who were Muslims, displayed a strong desire to return home with degrees in economics, commerce and accounting, not because of their own personal interest or abilities in these areas but for a nationalistic need for their countries to develop qualified professionals in the business world. Her results supported the idea that students from various cultures possess different achievement motivation factors for academic success related to both specific individual needs as well as strong cultural expectations and values. 
Cross-Cultural Research Studies on Achievement Motivation

A research study on achievement motivation attributes among Mexican American and Anglo American eighth grade students was carried out by Menchaca (1991). The purpose of the study was to determine a relationship between academic performance (grade point averages) and achievement motivation attributes of the two groups of students. Also, the 1969 Achieving Tendency Scales for males and females was administered to the two sample groups of sixty students each and the results of this test were used as predictors of achievement motivation. Additional information was gathered through personal interviews with a smaller number of sample subjects. A major finding from this study showed that the best predictor of academic success was the differences in attitudes towards success or failure held by students.

A study on achievement motivation and academic performance of Caribbean students attending postsecondary two and four year institutions on the east coast was conducted by Lewis (1991). Schmeck's Inventory of Learning Processes scale and the Mehrabian and Banks Achieving Tendency scales were administered to the sample. Results from this study indicated that academic success was related to self-concept/self-esteem based on past high school accomplishments and, that those students who completed high school in the Caribbean outperformed Caribbean students who 
graduated from American high schools.

Much of cross-cultural research has been conducted on the Japanese society as it compares to American society. In a research study conducted by the University of Michigan, Stevenson (1985) found that Japanese and Taiwanese children excelled in the areas of reading and mathematics as early as grade one as compared to American children. One factor which played an important role in the development of the Japanese and Taiwanese children was that Asian mothers had much higher expectations for their children and for their performance in school than did American mothers. For American mothers, more than $40 \%$ were satisfied with their children's mastery of the educational materials whereas only $10 \%$ of the Asian mothers were satisfied even though their children had consistently outperformed the American children. American mothers rated the attribute of ability as having greater importance for success than that of effort whereas the Asian mothers placed greater importance on effort.

Shigaki (1983, p. 16) has identified the attributes Japanese teachers try to foster in young children. They are sympathy, social conscious, cooperation, patience, perserverance, creativity and inquiry. These attributes define a humanistic view of people which is of value in Japanese society. In comparison, a study of American educators yielded different attributes ascribed to students in the 
United states. This list consists of honesty, selfconfidence, and independence. The American value system appears to be more self-centered and individualistic in comparison to the communal value system of Japan.

Since Miami-Dade Community College has such a varied international student population, a cross-cultural approach to the study of this student body is of value in understanding the similarities and differences among the students. In order to capture this information, the personal interviews will be directed so as to cover cultural activities and practices from the students' home countries which may influence achievement motivation in international students attending an academic institution.

Causal Attributions for Failure in a college placement Test Reiter (1989) conducted a study on the causal attributes for failure on a college placement test by high risk students at Miami-Dade Community College and based her research primarily on the theories of McClelland, Atkinson and Weiner. Using a causal-comparative approach, she surveyed 524 students; 327 students enrolled after taking a college placement test with 197 students who did not enroll at the institution after taking the placement test. The four causal attributes of effort, ability, luck and task difficulty were examined as influencing factors on the enrollment decisions of those subjects in attending MiamiDade Community College. 


\section{Summary}

This chapter provided the theoretical framework for this investigation on the causal attributes of achievement motivation on the academic success of international F-I visa students at Miami-Dade Community College. The contributions of both MCClelland and Weiner to an expanded theory of motivation was used as the basis for this study. In this manner, the internal need for achievement, $n$-ach, as well as the attributional approach, including $\mathrm{v}$-ach, could be united to explore this phenomenon among international F-I visa students.

Since the research population was comprised of students from over 137 different countries, the significance of cross cultural research and orientations on achievement motivation was explored. Questions concerning the cross-cultural similarities and differences in child-rearing practices, educational systems and societal expectations were addressed.

As Linton (Brameld, 1957, p. 170) summarizes, the importance of culture on the individual falls into four main statements 1) that the individual's early experiences exert a lasting effect upon his personality 2) that similar experiences will tend to produce similar personality configurations in the individuals who are subjected to them 3) that the techniques which the members of any society 
employ in the care and rearing of children are culturally patterned and will tend to be similar, although never identical, for various families with the society 4) that the culturally patterned techniques for the care and rearing of children differ from one society to another.

Therefore, in this study, the basic research question investigated was why international F-I visa students are motivated to achieve. While the study focused on achievement motivation, it also provided data on the importance of culture as a variable of achievement motivation as outlined in Linton's statements. The five specific research questions were addressed.

1. Do visa students differ from other foreign born students on identified causal attributes of achievement motivation for their success in college?

2. Do these causal attributes manifest themselves in higher academic success for F-1 visa students?

3. Does residency classification (international student, permanent resident, parolee) affect a change in achievement motivation factors?

4. Does acculturation into the American society and its accompanying values influence academic goals among international students?

5. Are there cultural differences in the importance of education and the techniques in instilling such values in children? 
The following chapter describes the methodology of the study, sample population, hypotheses to be tested as well as the statistics to be compiled. In addition, the various instruments used in the collection of the data are presented. 


\section{CHAPTER THREE: METHODOLOGY}

This study was conducted to research the causal attributes described by international F-1 visa students at Miami-Dade Community College as perceived causes for their achievement motivation for academic success. In this chapter, the research population and samples under investigation are described. A cross-cultural approach to research and its importance to this study are presented. The utilization of the data instruments, a questionnaire and the Guided Biography, are then described.

\section{Introduction}

The purpose of this study was to identify and compare the causal attributes of achievement motivation for academic success of Miami-Dade Community College/Wolfson Campus F-1 international visa students to other MDCC/Wolfson Campus foreign born students who have obtained residency status in the United States. Many factors, both internal and external to the students, may influence achievement motivation among individuals as reported in Chapter Two Review of the Literature. Of significant importance may be the variables of cultural relevancy and residency status on achievement motivation of international students.

Since this study incorporated both quantitative as well as qualitative methods, the data analysis was both statistical and descriptive. Quantitative dimensions of achieve- 
ment motivaton were measured by obtaining the sample subjects' grade point average by semester, the number of changes in majors, and the number of credits earned. The results from the Measurement of Achieve-ment Motivation Questionnaire (MAM) (Appendix A) to be administered will be presented.

In addition, to support the statistical data collected in the study, qualitative data from personal interviews (Appendix B) of a subset of the sample was provided. These guided biographies add personal historical information about the students' home countries and experiences. This information is not readily available from the Measurement of Achievement Motivation Questionnaire nor from the college's student record files.

As presented in Chapters one and Two, the basic research question studied was why $F-1$ international students are so motivated to achieve. The following five specific research questions were investigated.

1. Do visa students differ from other foreign born students on identified causal attributes of achievement motivation for their academic success?

2. Do these causal attributes manifest themselves in higher academic success for F-1 visa students?

3. Does residency classification (international student, permanent resident, parolee) affect a change in achievement motivation factors? 
4. Does acculturation into the American society and its accompanying values influence academic goals among international students?

5. Are there cultural differences in the importance of education and the techniques in instilling such values in children?

\section{Research Hypotheses}

In order to investigate these research questions, nine hypotheses were proposed for testing.

To research the question, "Do visa students differ from other foreign born students on identified causal attributes of achievement motivation for their success in college?", two research hypotheses were posited.

$\underline{H}_{1}$. F-1 international students will identify different causal attributes, internal dimensions of ability and effort, as perceived causes for their success as compared to those attributes identified by other foreign born students as measured by the Measurement of Achievement Motivation Questionnaire.

$\underline{\mathrm{H}}_{2} \cdot \mathrm{F}-1$ international students will identify different causal attributes, internal dimensions of ability and effort as perceived causes for their success as compared to those attributes identified by other foreign born students as described in narrative form through the Guided Biography Interview.

In response to the question, "Do these causal 
attributes manifest themselves in higher academic success for visa students?", three hypotheses were tested.

$\underline{\mathrm{H}}_{3}$. International visa students achieve higher grade point averages than other foreign born students.

$\underline{\mathrm{H}}_{4}$. International visa students complete more credit hours per semester than other foreign born students.

$\underline{H}_{5}$. International visa students have fewer changes in majors than other foreign born students.

To answer the question, "Does residency classification (international student, permanent resident, parolee) affect a change in achievement motivation factors?", one hypothesis was asked.

$\underline{H}_{6}$. International students identify the need to succeed in college in the United States since they will be leaving after completion of their studies significantly more often than other foreign born students as measured by responses to the Guided Biography Interview.

In response to the question, "Does acculturation into the American society and its accompanying values influence academic goals among international students?", one hypothesis was proposed.

$\underline{\mathrm{H}}_{7} \cdot \mathrm{F}-1$ international students maintain stronger cultural identities as compared to other foreign born students as measured by the Measurement of Achievement Motivation Questionnaire and by the responses to the Guided Biography Interview. 
To answer the question, "Are there cultural differences in the importance of education and the techniques in instilling such values in children?", the following two research hypotheses were asked.

$\underline{H}_{8}$. Achievement motivation attributes differ among countries as measured by subjects' responses to the Measurement of Achievement Motivation Questionnaire and responses to the Guided Biography Interview.

$\underline{H}_{9}$. Achievement motivation attributes within a country differ by gender as measured by achievement variables as grade point averages and responses on the Measurement of Achievement Motivation Questionnaire.

\section{Cross-Cultural perspectives}

Due to the varied nature of the international student population at Miami-Dade Community College, a cross-cultural approach to understanding the dynamics of this student population was required. Triandis and Brislin (1984) defined cross-cultural psychology as "the collective efforts of researchers who work among people who speak various languages, live in societies ranging from technologically unsophisticated to highly complex and industrialized, and who live under different forms of political organizations" (p. 1006).

Researchers view culture as influencing educational achievement. "They see it as a powerful predictor of children's motivation to do well in school" as stated by 
Cordes (1984, p. 51). Foreign born students are members of such cross-cultural groups and bring with them the values and norms of their home societies to this new setting in the United states.

Moreno and Di Vesta (1991) have expounded the importance of cross-cultural studies in that such studies provide a format for comparing cultures in specific areas. These cultural experiences influence both cognitive skills and information processing skills of individuals and, therefore, influence learning skills of students. However, they point out the caveat of not interpreting results of separate cross-cultural studies which employ different instruments, sample sizes, and subjectivity as measuring the same variable. Even the interpretation of results from replicated studies in various countries need to be analyzed from the perspective of the country in which the study took place not necessarily the first country in which the study was conducted.

\section{Causal-Comparison Research}

To research this topic, a causal-comparison research design was utilized. In a causal-comparison study, assumptions are postulated as to a relationship among specified variables which differ between groups. For example a change in variable $\mathrm{X}$ is accompanied by a change in variable $\mathrm{Y}$ over time. There may be a covariation between cause and effect with the cause preceding the effect 
(Sellitz, Wrightsman \& Cook, 1976).

Hypotheses are formulated to test these assumed relationships between variables and to control for the influence of other confounding variables on the outcomes. Randomization in selecting the study participants will decrease the effect of confounding variables on the observed results (Mouly, 1970). Alternative hypotheses may also be proposed to account for the observed outcomes (Borg \& Gall, 1983).

Since a tightly controlled experimental study where the subjects can be manipulated was not appropriate for this study, descriptive survey data was collected from historical records in the college's mainframe computer system as well as from the results of the Measurement of Achievement Motivation Questionnaire administration. The Guided Biography Interviews added ethnographic material on achievement motivation for review in this study.

It must be emphasized that the results of this study can not be interpreted as proving cause and effect correlations but as showing relationships among the named variables.

\section{Population of the study}

A computerized listing of all international students within the five residency classifications of students ( $F-1$ visa, resident aliens, asylees, parolees, and refugees) registered at the Wolfson Campus of Miami-Dade Community 
College for the winter term, January 1996 through April 1996 was generated. The estimated total student population comprised of the five different categories was 1,600 students on campus out of 5,600 collegewide.

This listing, however, was compiled after the $100 \%$ fee refund date, January 11th, to exclude all students who registered but did not pay for their tuition. These students were voided by the college's computer system by that date. Though registration and payment of classes do not guarantee attendance in classes, it was assumed that students who have registered and paid for their classes will be working toward an educational goal or specific degree.

In addition, residency status for students may change at any time during the semester, so for coding purposes of this study, the residency status of the students was as of the first day after the $100 \%$ refund date. There may be some students who had their residency status changed during the term but were still included in the sample.

Sample subjects.

The research population was comprised of all international students enrolled for the Winter term, January through April 1996 on the Wolfson Campus of Miami-Dade Community College. Applying random sampling procedures, a sample of 50 subjects (Sample $1 \underline{n}_{1}=50$ ) of international F-1 visa students was selected from the population of $\underline{\mathrm{N}}=225$, based upon the statistical formula of Isaac and Michael 
(1981). In addition, two other samples of foreign born students in residency categories of resident aliens (Sample $2 \underline{n}_{2}=50$ ), and a combination, due to the small number, of refugees, asylees, and parolees (Sample $3 \underline{n}_{3}=50$ ) were also selected.

As much as possible, the following variables were controlled for in selecting participants for this study:

1. Length of time in the United States. Only students who had completed at least one year of living in the United States and one year at MDCC were eligible for the study. By controlling the time factor, it was possible to limit differences in performance due to acculturation to the United states over time.

2. Language proficiency. To control for the differences in English language ability and its effects on performance, only students who had completed the English as a second Language program based upon a TOEFL score or who had tested into at least college prep English based upon the MAPS exam score were included.

3. Country locale. Since differences in achievement motivation may be related to the home country, subjects would be selected in proportion to the number of students from that country or area in the general MDCC F-1 visa student population.

4. Gender. Previous studies have shown that there are differences in academic performance and in achievement 
motivation based on gender. To research this phenomenon within this study, a sample of males and females in proportion to the general MDCC F-1 visa student population was selected.

\section{Research Instruments}

Measurement of Achievement Motivation Questionnaire (MAM)

The Measurement of Achievement Motivation Questionnaire developed by Ory and Poggio (1975) is theoretically based on the work of McClelland and Weiner. Since most of the work of McClelland incorporated the use of the Thematic Apperception Test cards, this type of projective test has limited use in group settings. Questions of the TAT's validity and reliability in measuring achievement motivation have been raised (Ory \& Poggio, 1975). Therefore, Ory and Poggio, after reviewing the literature at that time on achievement motivation, expanded their theory to encompass attributional descriptions of achievement motivation based on Weiner's studies as well.

Eight main categories were identified as related to achievement motivation: perseverance, success probability, personal characteristics, parental attributes, sex differences, choice behavior, reaction to success/failure, and accomplishments (Ory \& Poggio, 1975). These investigators developed an instrument, in three forms, consisting of 106 items each which addressed the eight categories. Using a four point Likert type scale (strongly agree, agree, 
disagree, strongly disagree) to evaluate each item, 1324 students from eight university/college populations were chosen to participate in their study. An equal amount of males to females were selected as well as freshman students and up through four undergraduate classes and graduate students as subjects in this study.

Test Items.

The 106 items were grouped by 15 factors encompassing the eight variables previously reported.

1. Task Orientation (Items: 1, 3, 12, 22, 65, 74, 75, $76,79,81,90,97,101,105)$ These items were related to the difficulty of tasks and activities a subject would choose. Responses were in agreement that high achievers were more likely to select tasks with moderate difficulty and equal chance for success/failure. Low achievers were more apt to choose a task with extreme difficulty or extreme ease.

2. Perserverance (Items: 8, 44, 48, 50, 58, 61, 96, 100) These items measured a subject's determination to complete a task or problem. High achievers are more willing to work on a problem longer than low achievers but are also more aware of their individual limits and give up sooner when they foresee failures. Though low achievers tend to work longer on tasks than high achievers, they will also concede failure and give up.

3. Parental Affection (Items: 14, 19, 21, 40, 45, 69, 
72, 82, 94) These items were directed at the subject's memory of early childhood and the interactions between parents and child. High achievers identified their parents as being less friendly and warm as compared to those of low achievers.

4. Fear of Failure (Items: 11, 15, 16, 26, 28, 39, $43,47,64,103)$ Items in this category measured a subject's concern for failure over success at a task. Whereas low achievers are motivated more by the fear of failing at a task, high achievers are more motivated by the possibility of success at the outcome of the task.

5. Social Acceptance (Items : $10,37,71,73,78,85$, 88, 89, 99) These items measure the subject's internal versus external concern for success. With high achievers, internal concern for success is more important than external concern for social approval of the outcome.

6. Reaction to Success/Failure (Items: 32, 41, 83, 91, 98, 102, 106) These items indicate the subject's reaction to success or failure of a task. With high achievers, following success at a difficult task, they will try more difficult tasks most often after taking short breaks. The reverse situation is applicable for low achievers.

7. Future Orientation (Items: 6, 38, 59, 63, 70, 77, 80) These items reflect the subject's attitude toward future goals and activities. In general, high achievers 
tend to be more future oriented in action and beliefs. 8. Involvement (Items: 2, 20, 29, 30, 52, 54, 93) Items in this category reflect the subject's scope of achievement in activities. Low achievers invest less commitment and involvement in activities and tasks as compared to high achievers.

9. Parental Restriction (Items: 25, 33, 60, 66, 104) The amount of parental limits or restrictions placed on a subject during his early childhood is measured by these items. Low achievers report very strict and limiting behaviors placed upon them by parents where high achievers report free and open environments with their parents.

10. Test-taking Behavior (Items: 5, 27, 35) These items measure the subject's behavior as measured by the amount of time they expend during test-taking situations. High achievers will spend more time on tasks and problems than low achievers.

11. Competitiveness (Items: 7, 9, 23, 24, 87, 92) These items measure the subject's degree of competition be it against others in a similar situation or in time in completing a problem. High achievers tend to be higher in overall competitiveness.

12. Independence (Items: 4, 34, 57, 68, 86) This category of items measures a subject's penchant for working in groups or alone. Low achievers prefer to work in groups whereas high achievers are more oriented towards working 
alone on tasks.

13. Rigidity (Items: 17, 18, 54, 55, 56) Items in this category assess the subject's flexibility in relationship to specific situations in life. High achievers are more flexible and adventurous in engaging in life activities.

14. Unidentified (Items: $36,42,84$ ) These three items failed to provide a common psychological explanation and no interpretation was made in relationship to achievement motivation.

15. Anticipatory Behavior (Items: 62, 95) These items measure the subject's behavior in preparing for future activities. High achievers are more future-oriented and are more willing to put forth effort in preparation for the future.

\section{Guided Biography Interviews}

To gather personal demographic information from a smaller number of participants in the study, a subset of subjects which will equal a total of 45 subjects (15 $\times 3$ samples) were chosen to complete a 15 to 20 minute interview. This interview followed the format of the Guided Biography (Levinson, 1988) where the interviewer directs the open-ended questions to be asked. The format of this interview was structured to gather information pertaining to the subject's early education and cultural experiences in the home country as well as the subject's current educa- 
tional progress at Miami-Dade Community College.

Though it may appear to be casual type of interaction between researcher and subject there is an underlying research base for the proposed questions. As Rohner (1975) stated:

The cross-culture survey method employs a worldwide sample of societies from the ethnographic record in anthropology. Relevant variables are coded in these ethnographies for the purpose of statistically testing hypotheses about the transcultural relationship between two or more psychological, social, cultural, or other variables. One of the strengths lies in its ability to help discover whether a worldwide relationship exists between two variables (p. 29).

In the review of the literature on achievement motivation, emphasis has been placed on cultural differences in child-rearing practices as having significant importance on motivation as shown in the research of Rosen (1956), Winterbottom (1958), and MCClelland (1951, 1955, 1967). Questions pertaining to child-rearing practices and activities will be asked to the subjects in this study during the guided biography interviews since this information is not available from the college's student records nor from the MAM profile. This information may yield interesting results for further investigation. 
Following the coding system of Bacon, Barry and Child (1967) in their study of child-rearing practices, the following categories will be used to analyze the students' self-reports from the Guided Biography Interviews: nurturance $(N)$, obedience (O), responsibility (R), assertiveness (A), self-reliance (S) and independence (I). Zern (1984) in his study of child-rearing variables in 110 societies further defined these categories by dividing them between societal goals and individualistic goals. Nurturance, obedience and responsibility lie within the realm of societal goals whereas assertiveness, self-reliance and independence are within the individual's realm.

For Zern (1984), a major difference in child-rearing practices was dependent on the gender of the child. He found that those variables within the societal realm were less consistent for the sexes but the individualistic variables where clearly higher for males. Interviewing Techniques and Activities

The Guided Biographies were structured to obtain information from the subjects on their family values towards education, societal emphasis on education and culture as a factor in achievement motivation (Appendix C). However, it was important to control for interviewer bias in the collection and interpretation of this data. In this study, only one interviewer was used to help control interviewer bias into the results. Since the interviewer may not have 
known the selected subjects, a short introductory period of approximately 3 minutes took place where the interviewer informed the participant of the nature of the study and its applications. During this time, it was expected that some rapport between the interviewer and subject emerged. It was at this time that the interviewer again reinforced the confidentiality aspect of the study (Bogdan \& Biklin, 1982).

Upon the completion of each individual interview, the researcher wrote a transcript of the interview from the field notes and interview form (Appendix B). The field notes served as an important element of the interview in that they capture not only descriptive material provided in the subject's narrative responses but also the affective responses displayed by the subject as noted by the researcher (Lofland \& Lofland, 1984).

Since the Guided Biography and the interview process is based upon a theoretical framework by Levinson, results may be generalized to other similar settings with limitations (Bogdan \& Biklin, 1982). In this study, the researcher reviewed the transcribed interviews and data collected which lead to a descriptive summary of results. These findings added additional support to the quantitative data collected. Validity and Reliability of the Data Collection Instruments

In this study, a combination of quantitative and qualitative data collection techniques and analyses was conducted. To obtain a subject's Grade Point Average, the 
number of semester credits earned and number of program of study changes, standard quantitative descriptive statistics were utilized through the colllege's mainframe computer system.

For the Measurement of Achievement Motivation Questionnaire, the categories listed previously in this section were derived by the researchers from an extensive review of the literature on achievement motivation. The original testing was completed on 1324 subjects, college students from freshmen through graduate students, on eight university/college populations in six states. From the original 153 items, statistical analyses of the data using three orthogonal rotations were conducted. An item was eliminated from the pool of items if it failed to load on any of the named factors. There were 106 items remaining on the questionnaire. Reliability was confirmed by retesting over a six week period by 92 subjects and internal consistency was assessed on 152 subjects by Cronbach's alpha (Ory \& Poggio, 1975, p. 10). Cronbach's alpha, also known as the alpha coefficient, measures internal consistency for an average of observations, items or rates used in a reliability analyses (Cronbach, 1990, p. 202). A few of the categories could better assess the construct of achievement motivation by the inclusion of additional items in such categories as indicated by the researchers of the instrument. 
In the area of ethnographic data collection, the Guided Biography is a qualitative instrument and procedure in that it provides a description of events and perceptions that have taken place for the subject. Though these techniques are not rigidly scientific in methodology as conducting a laboratory experiment, the qualitative approach to research study has been used in numerous studies by such well-known researchers as Margaret Mead, Max Weber and Erving Goffman (Bogdan \& Biklin, 1982). The Guided Biography was grounded in theory based on past studies on achievement motivation previously described. 


\section{CHAPTER FOUR: ANALYSIS OF DATA}

The purpose of this study was to identify the causal attributes of achievement motivation possessed by international F-1 visa students and to compare these attributes to those attributes of other immigrant student groups at Miami-Dade Community College. A desired result of this study was to increase the understanding of why international students are driven to succeed and to see if their needs were being met with the current support services offered on campus. It is hoped that other immigrant student groups could also benefit from these opportunities and support services. The research population and the results of the hypotheses testing are discussed in this chapter. Characteristics of the sample Subjects Data were collected from 150 selected foreign born students enrolled on the Wolfson campus of Miami-Dade Community College for the winter Term (95-2), January through April 1996. Three sample groups of 50 students each were randomly selected by residency status: 50 F-1 international visa students $(\underline{N}=225)$, 50 Permanent Resident students $(\underline{N}=585)$, and 50 other students comprised of parolees and asylees $(\underline{N}=516)$. Data were collected for each subject on the following variables: residency status, gender, age, country of origin, number of semesters at Miami-Dade Community College, Grade Point Average, major 
field of study, number of changes in majors, cumulative credits earned, and cumulative credits registered.

To be included in the pool of possible subjects for this study, all students must have had at least one year at Miami-Dade Community College. Students must have either originally scored into college English classes based on a MAPS exam score or have completed English as a Second Language courses as originally required by a TOEFL examination score now permitting them to be in college English by the 95-2 term.

The three groups under investigation in this study were the F-1 international students, Permanent Resident students and Other immigrant students. F-1 international students were admitted for postsecondary study at Miami-Dade Community college by obtaining a student visa from the federal Department of Immigration and Naturalization Services. These students made the choice to leave their home countries to obtain an academic degree in the United States and, in most cases, planned to return home upon the completion of these degrees. The Permanent Resident students were not born in the United States, but had been granted the right to remain indefinitely in the United states and to apply for American citizenship. The immigrant students falling into the other category were not born in the United States and were, in most cases, fairly recent arrivals compared to the Permanent Resident group. These students have temporary 
permission to be in the United states and, in most cases, to file for permanent residency. However, in all probability not all students in this group will be granted permanent residency status.

In the original methodology design, it was planned that the Permanent Resident students and other immigrant students would be selected to match as closely as possible the F-1 international student group on such variables as age, gender, and country of origin. When the computerized listing of students was generated, it was found that only one variable, gender, could be used as a match by all three groups. Therefore, all groups have 24 randomly selected males and 26 randomly selected females each for a total population of 150 .

Age

Though the pool of potential subjects was quite large for the Permanent Resident students and Other students with over 500 subjects each, when the independent variable of age was factored into the selection process, it showed that there were not enough "younger" subjects in the Permanent Resident and other categories to be matched to those selected for the F-1 international student sample. Table 1 shows the distribution of the age variable categories by residency status and indicates that $82 \%$ of the $50 \mathrm{~F}-1$ international student sample subjects fell within the combination of age brackets of $18-20$ and $21-23$ whereas the 
number was only $52 \%$ for the Permanent Resident group and $42 \%$ for the Other group within the same age brackets. Table 2 presents the mean age score by residency status for each sample with the mean for all three groups being 23.79 years. There was a significant difference between mean ages as shown by the F ratio, $\underline{E}(2,147)=9.83, \underline{p}<.0001$ with the F-1 international subjects being significantly younger than the other two groups using Duncan's pairwise comparison procedure at the 5\% significance level. Also, Permanent Resident students are significantly younger than other students. Table 1

Distribution of Age by Residency Status

\begin{tabular}{|c|c|c|c|c|c|c|}
\hline \multirow{2}{*}{$\begin{array}{l}\text { Age } \\
18-20\end{array}$} & \multicolumn{2}{|c|}{$\begin{array}{l}\text { F-1 Int'l } \\
\text { Count Pct }\end{array}$} & \multicolumn{2}{|c|}{$\begin{array}{l}\text { Per Res } \\
\text { Count Pct }\end{array}$} & $\begin{array}{l}\text { Other } \\
\text { Count }\end{array}$ & Pct \\
\hline & 25 & 50.0 & 14 & 28.0 & 10 & 20.0 \\
\hline $21-23$ & 16 & 32.0 & 12 & 24.0 & 11 & 22.0 \\
\hline $24-26$ & 4 & 8.0 & 11 & 22.0 & 7 & 14.0 \\
\hline $27-30$ & 3 & 6.0 & 7 & 14.0 & 13 & 26.0 \\
\hline $30+$ & 2 & 4.0 & 6 & 12.0 & 9 & 18.0 \\
\hline Total & 50 & 100.0 & 50 & 100.0 & 50 & 100.0 \\
\hline
\end{tabular}


Table 2

One Way Analysis of Variance on Age by Residency Status

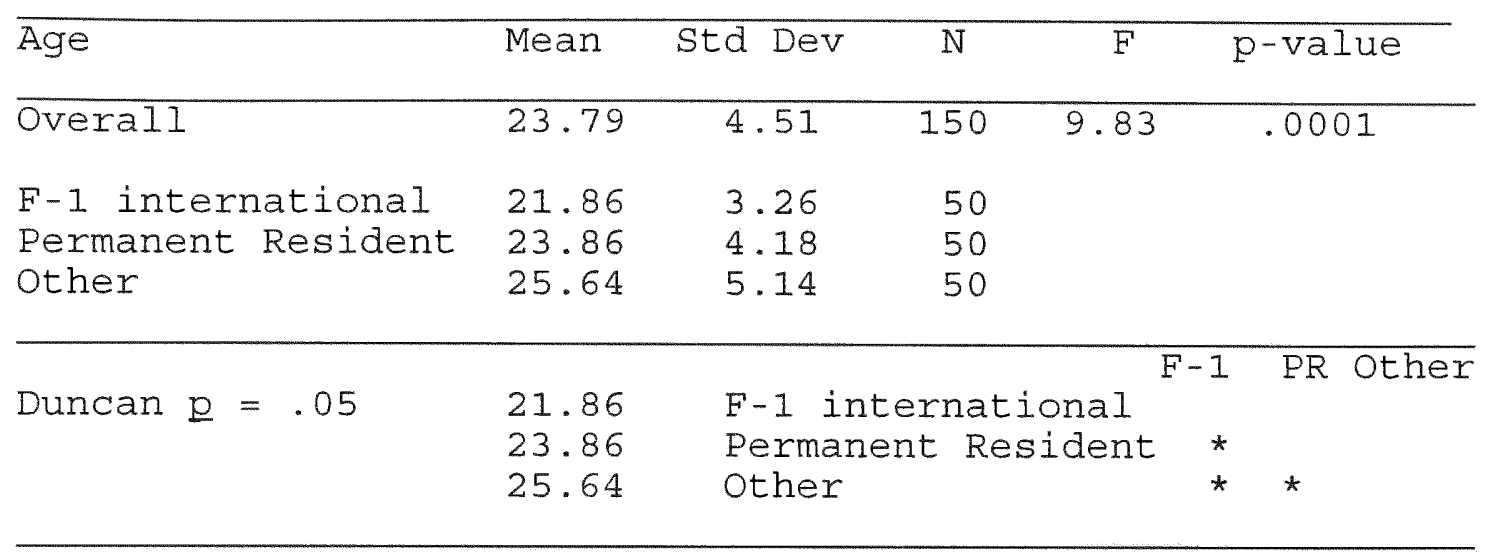

Country of origin

The three sample groups' subjects were planned to be matched by country of citizenship, to have equal representation in each group; however, there were 27 different countries represented in the F-1 international student group and only 11 countries in the Permanent Resident student group and 10 countries in the other immigrant student group. It was also not possible to match them by geographic areas because the F-I international student population was represented by six geographic areas, South America, Europe, Asia, Caribbean, Middle East and Central America, whereas there were no subjects from Asia in either the Permanent Resident group or the other group. As shown in Table 3, the majority of students in the Permanent Resident group and other group came from countries in South America. The F-1 
international group's distribution is more spread out throughout the regions. A complete distribution breakdown by countries is found in Appendix C.

Table 3

Distribution of Geographic Areas by Residency Status

\begin{tabular}{|c|c|c|c|c|c|c|}
\hline \multirow{3}{*}{ Area } & \multicolumn{4}{|c|}{ Residency Status } & \multirow{3}{*}{$\begin{array}{l}\text { Other } \\
\text { Count }\end{array}$} & \multirow[b]{3}{*}{ PCt } \\
\hline & \multicolumn{2}{|c|}{$F-1$ Int' 1} & \multicolumn{2}{|c|}{ Per Res } & & \\
\hline & Count & Pct & Count & Pet & & \\
\hline South America & 15 & 30.0 & 32 & 64.0 & 27 & 54.0 \\
\hline Europe & 9 & 18.0 & 2 & 4.0 & 1 & 2.0 \\
\hline Asia & 5 & 10.0 & 0 & 0.0 & 0 & 0.0 \\
\hline Caribbean & 11 & 22.0 & 9 & 18.0 & 8 & 16.0 \\
\hline Middle East & 4 & 8.0 & 1 & 2.0 & 1 & 2.0 \\
\hline Central America & 6 & 12.0 & 6 & 12.0 & 13 & 26.0 \\
\hline Total & 50 & 100.0 & 50 & 100.0 & 50 & 100.0 \\
\hline
\end{tabular}

Note. South America includes Argentina, Brazil, Chile, Colombia, Ecuador, Peru, Uruguay, Venezuela; Europe includes France, Hungary, Italy, Netherlands, Spain, Sweden; Asia includes China, India, Japan; Caribbean includes Cuba, Dominican Republic, Haiti, Jamaica, Trinidad; Middle East includes Israel, Lebanon, Sudan; Central America includes 
Nicaragua, Mexico, Panama.

* $\mathrm{X}^{2}$ not valid due to expected frequency count $<5$ in several cells.

Number of Semesters at Miami-Dade Community College

While all sample subjects had to have at least one year at Miami-Dade Community College, Permanent Resident and Other subjects did not necessarily have continuous one year enrollment at the college. All international F-1 visa students had continuous enrollment. It was impossible to calculate the exact number of years subjects had lived in the United States and in Miami from the college's computerized data collection system. However, the independent variable of number of semesters at Miami-Dade Community College was tabulated as shown in Tables 4 and 5 . The mean number of semesters of all groups was 6.30 with the highest for Permanent Residents $(\underline{M}=6.80)$ and the lowest for Other students $(\underline{M}=5.30)$. A significant $F$ ratio was computed, $\underline{F}(2,147)=3.59, \underline{p}<.03$. Duncan's post hoc test showed that the other students were significantly lower than Permanent Resident students and F-1 students. 
Table 4

Distribution of Number of Semesters at Miami-Dade Community College by Residency Status

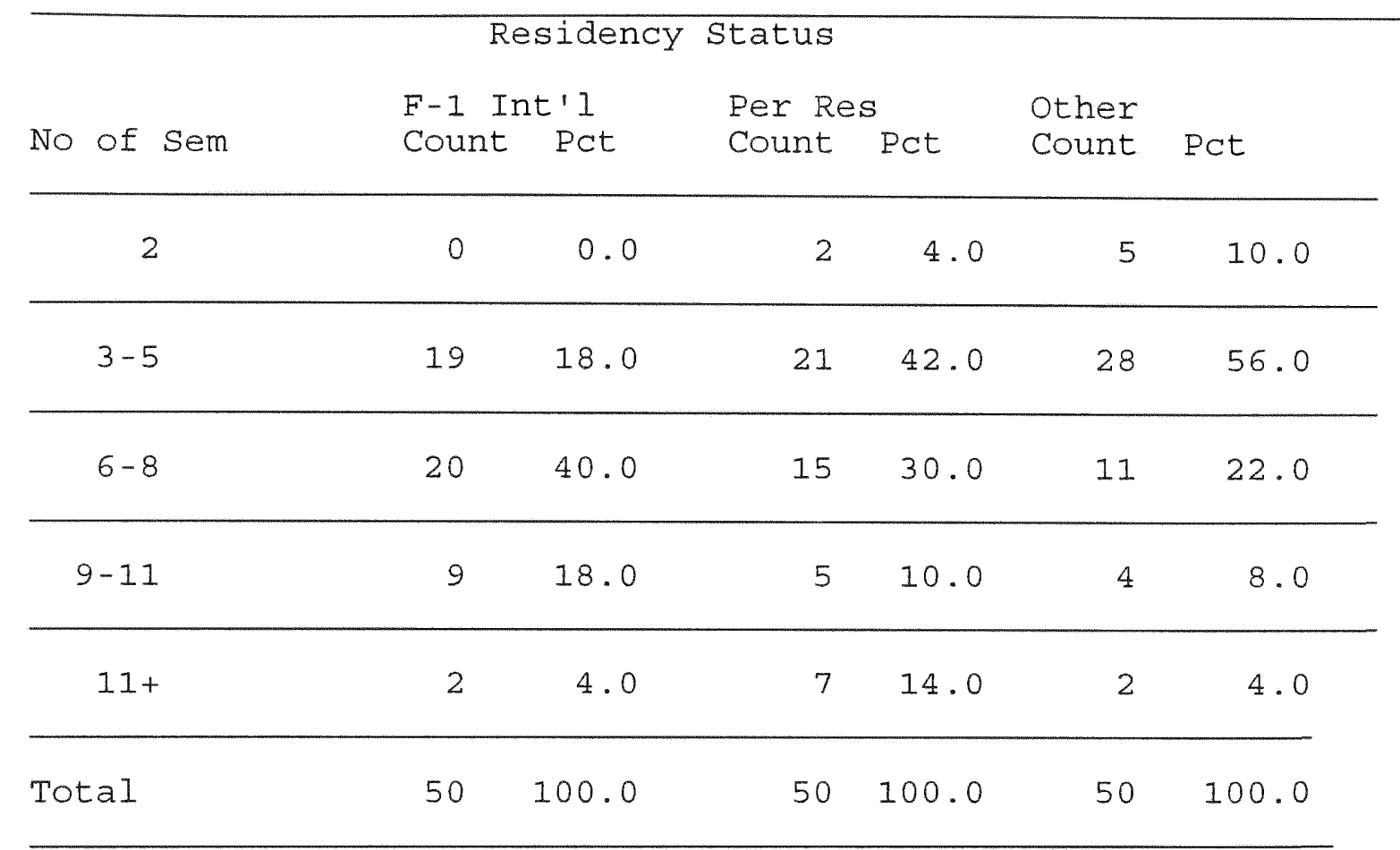

Table 5

One Way Analysis of Variance on Number of Semesters at Miami-Dade Community College by Residency status

\begin{tabular}{|c|c|c|c|c|c|}
\hline No of sem & Mean & std Dev & $\mathrm{N}$ & $F$ & $p$-value \\
\hline Overall & 6.30 & 3.07 & 150 & 3.59 & .0300 \\
\hline $\begin{array}{l}\text { F-I international } \\
\text { Permanent Resident } \\
\text { Other }\end{array}$ & $\begin{array}{l}6.58 \\
6.80 \\
5.30\end{array}$ & $\begin{array}{l}2.26 \\
3.96 \\
2.55\end{array}$ & $\begin{array}{l}50 \\
50 \\
50\end{array}$ & & \\
\hline Duncan $\mathrm{p}=.05$ & $\begin{array}{l}5.30 \\
6.58 \\
6.80\end{array}$ & $\begin{array}{l}\text { Other } \\
F-1 \text { int } \\
\text { Permane }\end{array}$ & $\begin{array}{l}\text { nati } \\
=\text { Res }\end{array}$ & $\begin{array}{l}\text { Ot] } \\
\text { nal } \\
\text { dent }\end{array}$ & $\begin{array}{lll} & F-1 & P R \\
* & & \\
* & & \end{array}$ \\
\hline
\end{tabular}


Data Collection Procedures for the Measurement of Achievement Motivation Questionnaire

Each subject was sent a letter explaining the purpose of the study and asking the subject to complete a 106 item questionnaire, the Measurement of Achievement Motivation Questionnaire by Ory and Poggio (1975). A self-addressed return envelope was provided for easy access. From the initial letter, 84 completed forms were returned by mail and 47 completed forms were personally turned in at the office. Three letters were returned due to incorrect addresses. A follow up telephone call was made to the 19 selected subjects who had failed to respond to the letter. All 19 subjects were contacted and either were sent a new form or came to the office to complete the form. A total of 150 questionnaires (100\%) were finally collected. Analysis of the Measurement of Achievement Motivation Questionnaire

The 106 items were grouped into fifteen variables measuring achievement motivation: 1) Task Orientation 2) Perseverance 3) Parental Affection 4) Fear of Failure 5) Social Acceptance 6) Success/Failure 7) Future Orientation 8) Involvement 9) Parental Restriction 10) Testtaking 11) Competitiveness 12) Independence 13) Rigidity 14) Unidentified and 15) Anticipatory Behavior. The three items, 36,42 and 84 which fell into the variable "unidentified" were not defined. The number of items per 
category varied with two items being the lowest number per category up to 14 items included in one variable. A breakdown of the variables by items is provided in Appendix B. In order to research the basic research question as to why international students are motivated to achieve, four research questions were posited with a total of nine hypotheses to be answered. Specific research question 1: Do visa students differ from other foreign born students on identified causal attributes of achievement motivation for their academic success? To address this question, two hypotheses were proposed. Null Hypothesis 1 stated: There are no significant differences in the identified causal attributes for achievement motivation between International students, Permanent Resident students and Other immigrant students as measured by the Measurement of Achievement Motivation Questionnaire.

The scores from the 106 items of the Measurement of Achievement Motivation Questionnaire were tabulated into the 15 variables of achievement motivation and were then analyzed by using ANOVA techniques. Each significant ANOVA result was then further analyzed by Duncan's Post Hoc Mean Comparison procedure carried out at a 5\% level of significance. Explanations of the results from the Measurement of Achievement Motivation Questionnaire relating to achievement motivation theory are presented in Chapter Five. 


\section{Task orientation.}

On the variable of Task Orientation which states that high $\mathrm{n}$-ach achievers, most often choose tasks of moderate difficulty with a 50/50 percent probability of success, and that low $\mathrm{n}$-ach achievers most often select either very easy or extremely difficult tasks, there was a significant F ratio, $\underline{E}(2,147)=45.22, \underline{p}<.0001$, with the mean score for F-1 international students $(\underline{M}=36.04)$ being significantly higher than for Permanent Resident $(\underline{\underline{M}}=31.18)$ and the other subjects $(\underline{M}=32.64)$ as shown in Table 6 . From past studies using this Measurement of Achievement Motivation Questionnaire, results indicated that high achievers scored lower on this variable than did low achievers. However, in this research study, the F-1 international students' mean score was significantly higher than the other two groups, Permanent Resident and other. This would indicate that F-1 international students were more likely to attempt more difficult tasks with less probability of success than to try easier tasks. 
Table 6

One Way Analysis of Variance on Task Orientation Scores by Residency Status

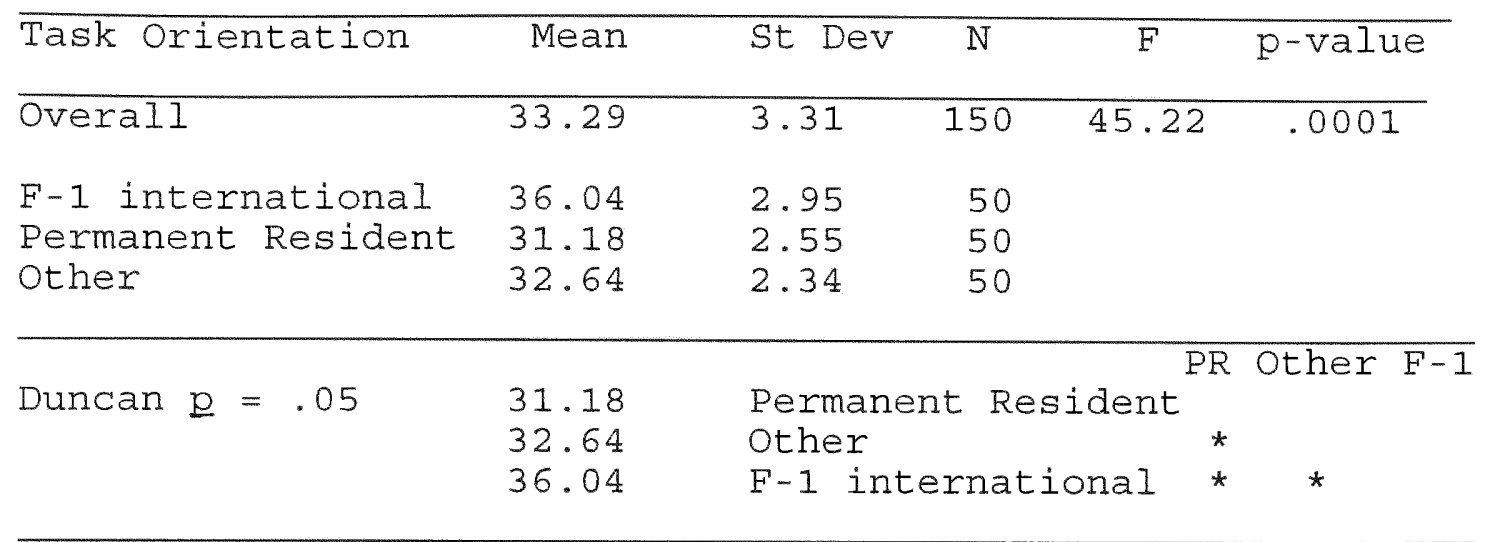

\section{Perseverance.}

For the variable of Perseverance which measures the willingness of the subject to work extra time on a task but also to realize the subject's limit of ability, a significant $F$ ratio, $E(2,147)=68.28, \underline{P}<.0001$, was found with F-1 international students' mean $(\underline{M}=25.16)$ significantly higher than the mean of the Permanent Resident students $(\underline{M}=21.62)$ and the Other students $(\underline{M}=22.48)$ as shown in Table 7 .

These data on Perseverance show that F-1 international students are more willing to work on problems longer than low $\mathrm{n}$-ach achievers but are also ready to admit their limitations or to see their lack of ability after awhile and move on to another task. Low achievers give up easily and do not expend additional time and effort in working on difficult problems. 
Table 7

One Way Analysis of Variance on Perseverance Scores by Residency Status

\begin{tabular}{|c|c|c|c|c|c|}
\hline Perseverance & Mean & Std Dev & $\mathrm{N}$ & $\mathrm{F}$ & $\overline{p-v a l u e}$ \\
\hline Overall & 23.09 & 2.18 & 150 & 68.28 & .0001 \\
\hline F-1 international & 25.15 & 1.90 & 50 & & \\
\hline Permanent Resident & 21.62 & 1.29 & 50 & & \\
\hline Other & 22.48 & 1.49 & 50 & & \\
\hline Duncan $\underline{p}=.05$ & $\begin{array}{l}21.62 \\
22.48 \\
25.16\end{array}$ & $\begin{array}{l}\text { Permane } \\
\text { Other } \\
\text { F-1 int }\end{array}$ & $\begin{array}{l}\text { Res: } \\
\text { hatic }\end{array}$ & $\begin{array}{l}\text { PR } \\
\text { dent } \\
\text { nal * }\end{array}$ & $\begin{array}{l}\text { Other F-1 } \\
\text { * }\end{array}$ \\
\hline
\end{tabular}

Parental Affection.

The variable of Parental Affection measures a subject's childhood memories of parental affection. High achievers tend to see their parents as less warm and friendly than low n-ach achievers. The analysis of variance on this variable of Parental Affection provided a significant $F$ ratio, $\underline{F}(2,147)=15.88, \underline{p}<.0001$, with the $F-1$ international students scoring significantly higher $(\underline{M}=28.32)$ than the Permanent Resident group $(\underline{M}=26.30)$ and the other group $(\underline{M}=26.10)$ as displayed in Table 8. The F-1 international students indicated that their parents were lacking in warmth as compared to the other groups' parents. 
Table 8

One Way Analysis of Variance on Parental Affection Scores by Residency Status

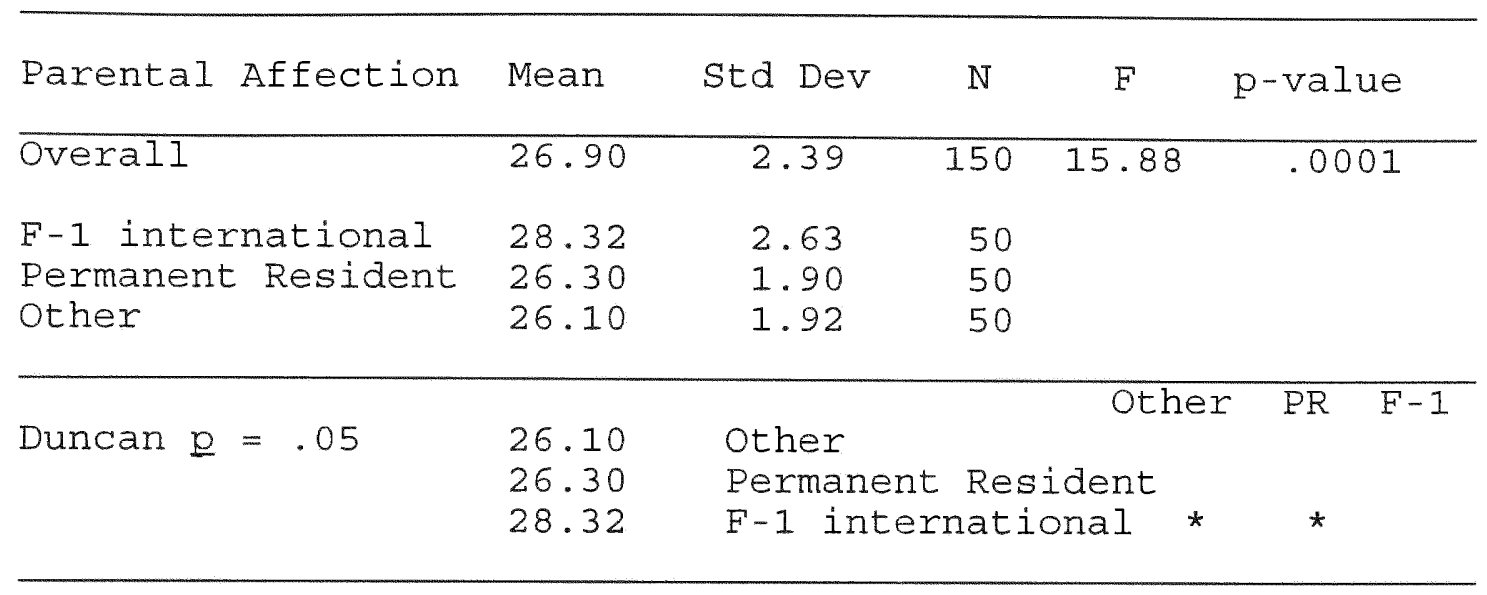

Fear of Failure.

The fourth variable, Fear of Failure, measures a subject's motivation for completing a task. Low n-ach achievers are more motivated by the fear of failure than by the possibility of success. The opposite is the case for high n-ach achievers. Higher scores on this variable indicate a stronger fear of failure usually associated with low achievers. A significant mean difference was found with the $F$ ratio as $\underline{E}(2,147)=23.20$, $\underline{\mathrm{p}}<.0001$. The $\mathrm{F}-1$ international students' mean for this variable $(\underline{M}=22.68)$ was significantly lower than the other two groups, the Permanent Resident group mean $(\underline{M}=25.42)$ and other group mean $(\underline{M}=25.02)$ as shown in Table 9. F-1 international students are motivated by the probability of success, not the fear of 
failure.

Table 9

One Way Analysis of Variance on Fear of Failure Scores by Residency status

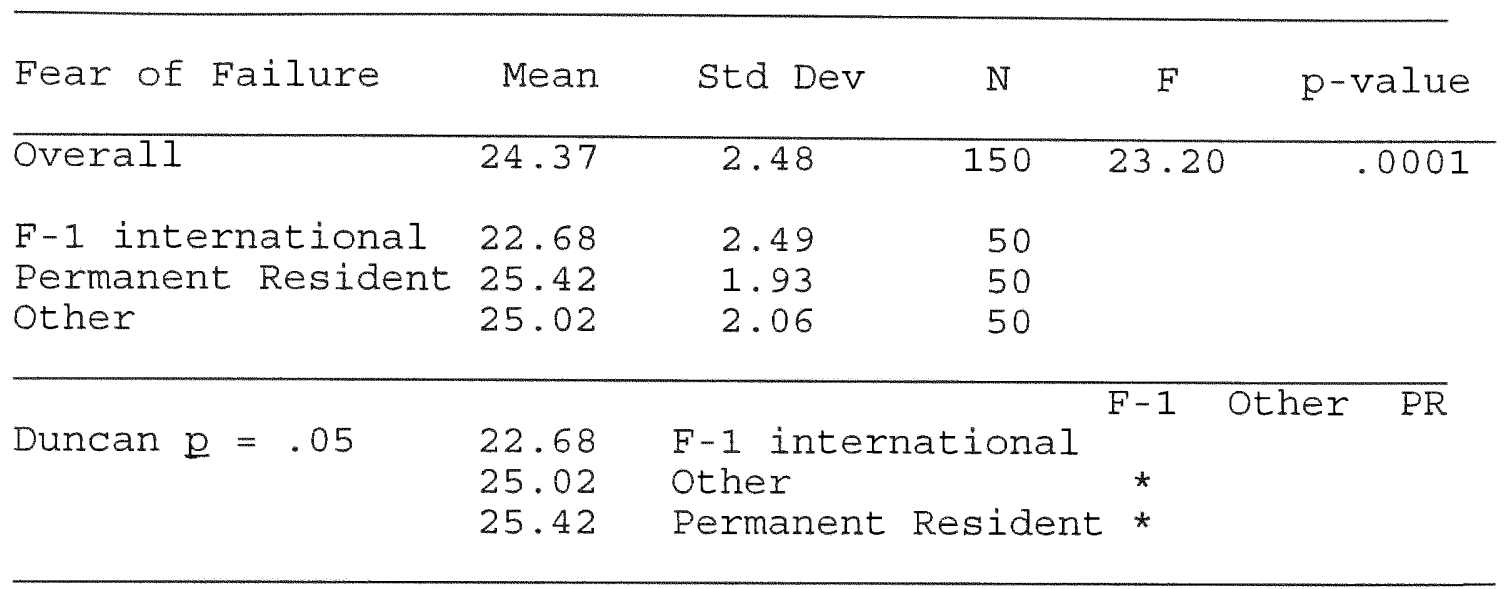

Social Acceptance.

Social Acceptance, the fifth variable, is more associated with internal motivation than societal pressure for motivation. Research has shown that high n-ach achievers are motivated by personal needs rather than concern for societal needs or outcomes. F-1 international students, in many cases, have come to the United states to study to meet a need for qualified workers back in their home country and may, therefore, have a strong connection with societal needs. The lower the mean score, the higher the tendency for internal motivation. A significant $F$ ratio was produced, $\underline{\mathrm{F}}(2,147)=140.66, \underline{\mathrm{p}}<.0001$. The $\mathrm{F}-1$ international subjects showed a higher internal need for 
achievement motivation than for societal concerns as shown by the mean score $(\underline{M}=18.36)$ on this variable compared to the mean of the Permanent Resident group $(\underline{M}=24.16)$ and the mean of the other group $(\underline{M}=24.00)$ as depicted in Table 10. Table 10

One Way Analysis of Variance on Social Acceptance Scores by Residency Status

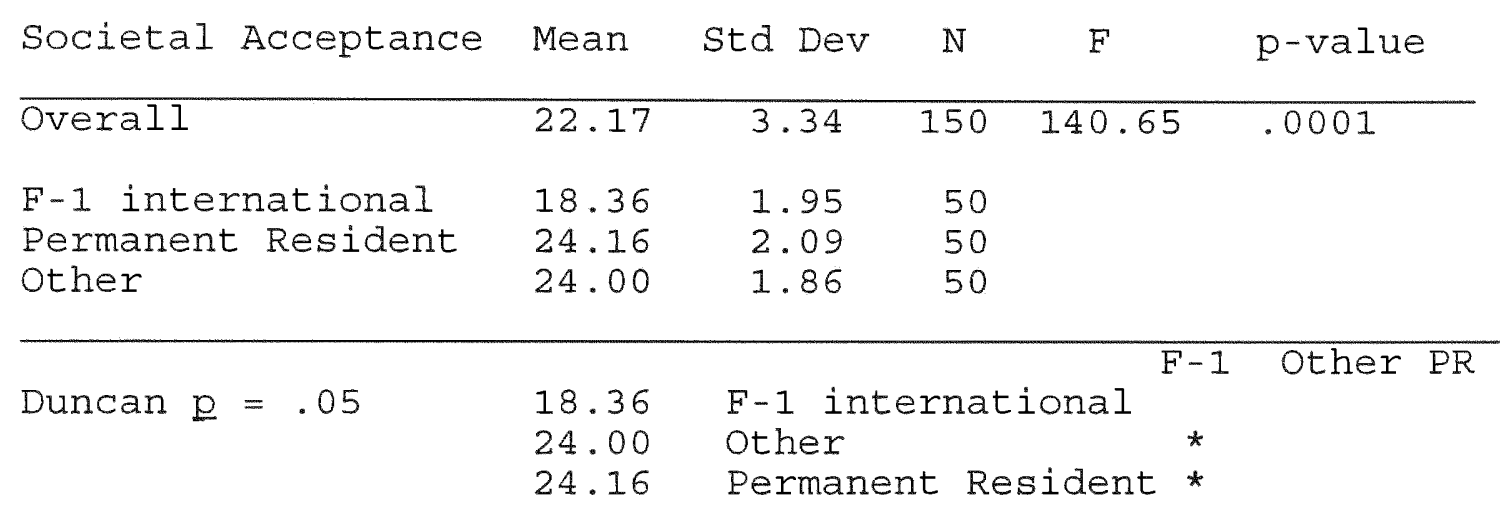

\section{Success/Failure.}

The Success/Failure variable indicates a subject's type of behavior after the completion of a task. After a successful completion of a task, high achievers will usually try a more difficult task or, in the case of failure, an easier task. In addition, high achievers will usually take a short break between the successful completion of a task. No significant difference was found between groups for the Success/Failure variable as shown by the $F$ ratio in Table 11, $\underline{E}(2,147)=2.69, \underline{p}>.07$.

Table 11 
One Way Analysis of Variance on Success/Failure Mean Scores by Residency Status

\begin{tabular}{lccccc}
\hline Success/Failure & Mean & Std Dev & N & F & P-value \\
\hline Overall & 20.60 & 1.53 & 150 & 2.69 & .0713 \\
& & & & & \\
F-1 international & 20.62 & 1.70 & 50 & & \\
Permanent Resident & 20.94 & 1.39 & 50 & & \\
Other & 20.24 & 1.42 & 50 & & \\
\end{tabular}

Future orientation.

The Future Orientation variable is associated with a consideration of time factor. High n-ach achievers are more focused on future activities than low achievers. A low score on this variable indicates a strong focus on future orientation. No significant $F$ ratio, $\underline{E}(2,147)=1.12, \underline{p}>.32$, was found with all three groups having means in the middle range where the range is 7 to 28 . The $F-1$ international mean $(\underline{M}=17.16)$, Permanent Resident mean $(\underline{M}=16.78)$, Other group mean $(\underline{M}=16.88)$ are shown in Table 12 .

Table 12

One Way Analysis of Variance on Future orientation Scores by Residency status

\begin{tabular}{lccccc}
\hline Future Orientation & Mean & Std Dev & N & F & P-value \\
\hline Overall & 16.94 & 1.31 & 150 & 1.12 & .3290 \\
& & & & & \\
F-1 international & 17.16 & 1.28 & 50 & & \\
Permanent Resident & 16.78 & 1.17 & 50 & & \\
Other & 16.88 & 1.48 & 50 & & \\
& & & & & \\
\end{tabular}




\section{Involvement.}

Involvement, the eighth variable, shows a subject's active participation in a task. High achievers show greater participation in most tasks as compared to low achievers. However, there were no significant differences among groups as shown by the $F$ ratio, $\underline{F}(2,147)=2.37, \underline{p}>.09$, in Table 13. A low mean score indicates greater participation in a task, usually evidenced by high achievers where the overall range of scores is $7-28$. The three group means were in the middle range: $F-1$ international mean $(\underline{M}=18.98)$, Permanent Resident mean $(\underline{M}=19.62)$, Other mean $(\underline{M}=19.30)$.

Table 13

One Way Analysis of Variance on Involvement Scores by Residency Status

\begin{tabular}{lccccc}
\hline Involvement & Mean & Std Dev & $N$ & $F$ & p-value \\
\hline Overall & 19.30 & 1.48 & 150 & 2.37 & .1000 \\
& & & & & \\
F-1 international & 18.98 & 1.25 & 50 & & \\
Permanent Resident & 19.62 & 1.60 & 50 & & \\
Other & 19.30 & 1.52 & 50 & & \\
\hline
\end{tabular}

Parental Restrictiveness.

The variable of Parental Restrictiveness indicates the type of home environment the subject encountered while growing up. High achievers reported that they came from 
unrestrictive type households. A low score would indicate a relatively free environment which is related to high achievers. A significant difference between means was found with the $F$ ratio as $\underline{E}(2,147)=8.82, \underline{p}<.0004$ as shown in Table 14. However, in this study, the F-1 international students' mean score $(\underline{M}=14.38)$ was significantly higher than that of the Permanent Resident group $(\underline{M}=13.70)$ and Other group $(\underline{M}=13.14)$ signifying that $F-1$ international students came from more restrictive households.

Table 14

One Way Analysis of Variance on Parental Restrictiveness Scores by Residency Status

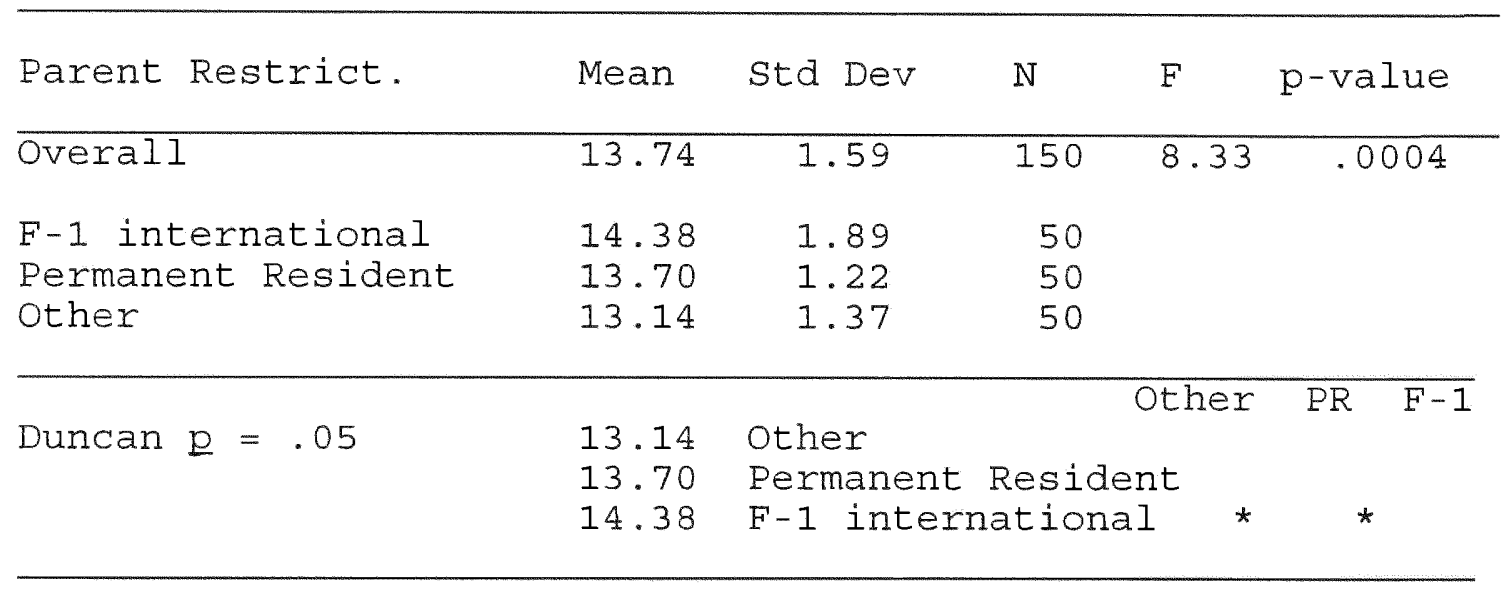

Testtaking.

This variable indicates that high achievers will usually spend more time on solving a problem than low achievers. A low score on this variable indicates a higher degree of time spent on testtaking. Results from the variable 
Testtaking were not significant as indicated by the $F$ ratio, $\underline{F}(2,147)=1.66, \underline{p}>.19$, as shown in Table 15. All three groups' means were in the middle range of the scale where the range of scores is from 3 to 12 : F-1 international mean $(\underline{M}=7.62)$, Permanent Resident mean $(\underline{M}=7.82)$, Other group mean $(\underline{M}=8.04)$.

Table 15

One Way Analysis of Variance on Testtaking Scores by Residency Status

\begin{tabular}{lcrrrr}
\hline Testtaking & Mean & Std Dev & N & F & P-value \\
\hline Overall & 7.83 & 1.16 & 150 & 1.66 & .1932 \\
& & & & & \\
F-1 international & 7.62 & 1.35 & 50 & & \\
Permanent Resident & 7.82 & 1.00 & 50 & \\
Other & 8.04 & 1.07 & 50 & & \\
& & & & & \\
\hline
\end{tabular}

Competitiveness.

On the variable of Competitiveness, high $\mathrm{n}$-ach

achievers tend to have high levels of competitiveness. They prefer to work alone as opposed to working in groups and for personally feeling responsible for the outcome of a task. In addition, high achievers enjoy competing against the clock for the solution of a problem. For this variable, a low score would indicate a preference for working alone. From the data in this study, it shows that there is a significant $F$ ratio, $\underline{E}(2,147)=10.15, \underline{p}<.0001$, as shown in Table 16. However, instead of the F-1 inter- 
national students' mean being the lowest to indicate a preference for working alone, the mean ( $\underline{M}=17.42)$ was significantly higher than the Permanent Resident group mean $(\underline{M}=15.98)$ and the other group mean $(\underline{M}=16.40)$. In this study, F-1 international students prefer to work in group settings.

Table 16

One Way Analysis of Variance on Competitiveness Scores by Residency Status

\begin{tabular}{|c|c|c|c|c|c|}
\hline Competitiveness & Mean & std Dev & $\mathrm{N}$ & $\mathrm{F}$ & $p$-value \\
\hline Overall & 16.60 & 1.74 & 150 & 10.15 & .0001 \\
\hline $\begin{array}{l}\text { F-1 international } \\
\text { Permanent Resident } \\
\text { Other }\end{array}$ & $\begin{array}{l}17.42 \\
15.98 \\
16.40\end{array}$ & $\begin{array}{l}1.78 \\
1.12 \\
1.91\end{array}$ & $\begin{array}{l}50 \\
50 \\
50\end{array}$ & & \\
\hline Duncan $\mathrm{p}=.05$ & $\begin{array}{l}15 \cdot 98 \\
16.40 \\
17.42\end{array}$ & $\begin{array}{l}\text { Permanent } \\
\text { Other } \\
\mathrm{F}-1 \text { intern }\end{array}$ & $\begin{array}{l}\text { Resid } \\
\text { lation }\end{array}$ & $\begin{array}{l}\text { PR } \\
\text { ent } \\
\text { al * }\end{array}$ & other $F-1$ \\
\hline
\end{tabular}

Independence.

The variable Independence is closely related to that of Competitiveness which measures the subject's tendency to engage in individual activities instead of group projects. As with the variable of Competitiveness, the lower the mean score, the more independent the subject tends to be in regards to working alone. High $\mathrm{n}$-ach achievers usually prefer to work alone. There is a significant F ratio, $\underline{F}(2,147)=40.23, \underline{p}<.0001$, as shown on Table 17. However, 
instead of scoring the lowest mean, the F-1 international students scored the highest mean $(\underline{M}=13.92)$ significantly different as compared to the Permanent Resident subjects $(\underline{M}=11.14)$ and the other subjects $(\underline{M}=11.60)$ on this variable.

Table 17

One Way Analysis of Variance on Independence Scores by Residency Status

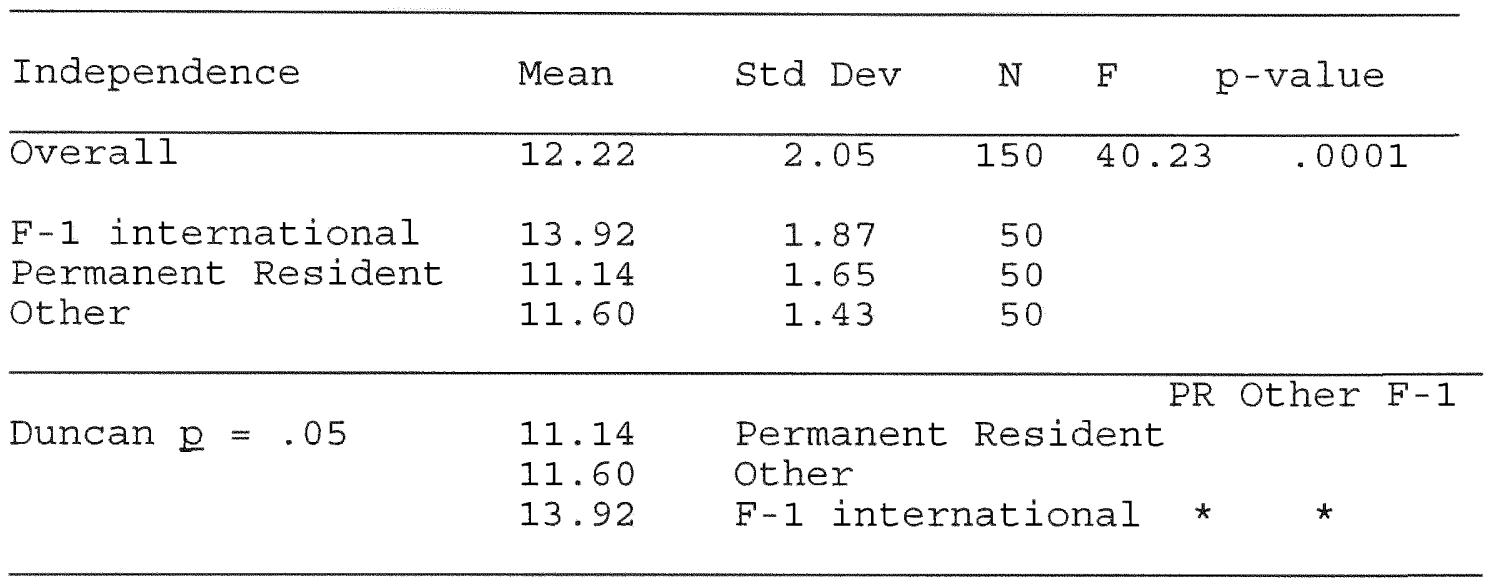

\section{Rigidity.}

For the variable of Rigidity, high achievers show more flexibility and more adventurous behavior in working through situations. A lower mean score on this variable indicates a greater need for flexibility. A significant $F$ ratio was found, $F(2,147)=9.14, \underline{p}<.0002$, as indicated on Table 18 . The F-1 international students' mean score $(\underline{M}=13.28)$ was significantly lower than that of the other two groups, Permanent Resident $(\underline{M}=14.38)$ and Other $(\underline{M}=14.02)$. As the results indicated, F-1 international students require more 
flexibility in their activities and tend to be more adventurous, such as studying abroad.

Table 18

One Way Analysis of Variance on Rigidity Scores by Residency Status

\begin{tabular}{|c|c|c|c|c|c|}
\hline Rigidity & Mean & Std Dev & $\mathrm{N}$ & $F$ & $p$-value \\
\hline Overall & 13.89 & 1.38 & 150 & 9.14 & .0002 \\
\hline $\begin{array}{l}\text { F-1 international } \\
\text { Permanent Resident } \\
\text { Other }\end{array}$ & $\begin{array}{l}13 \cdot 28 \\
14.38 \\
14.02\end{array}$ & $\begin{array}{l}1.44 \\
1.10 \\
1.36\end{array}$ & $\begin{array}{l}50 \\
50 \\
50\end{array}$ & & \\
\hline Duncan $\underline{\mathrm{p}}=.05$ & $\begin{array}{l}13.28 \\
14.02 \\
14.38\end{array}$ & $\begin{array}{l}\text { F-1 interr } \\
\text { Other } \\
\text { Permanent }\end{array}$ & Resio & $\operatorname{lal}^{\mathrm{F}-1}$ & $\begin{array}{l}1 \text { Other PR } \\
\star \\
\star\end{array}$ \\
\hline
\end{tabular}

Unidentified.

The fourteenth variable, Unidentified, was not associated with any specific theory of achievement motivation as reported by the authors of the Measurement of Achievement Motivation Questionnaire, Ory and Poggio (1975). There was a significant $F$ ratio for the three groups on this variable, $\underline{E}(2,147)=9.32, \underline{\underline{p}}<.0002$, as shown on Table 19 . The mean score for $\mathrm{F}-1$ internationals was significantly lower $(\underline{M}=6.82)$, followed by the mean score of the Permanent Resident group $(\underline{M}=7.00)$ and the Other group $(\underline{M}=7.68)$. However, no interpretation of this data is provided since these three items were not identified with an 
achievement motivation theory.

Table 19

One Way Analysis of Variance on Unidentified Scores by Residency Status

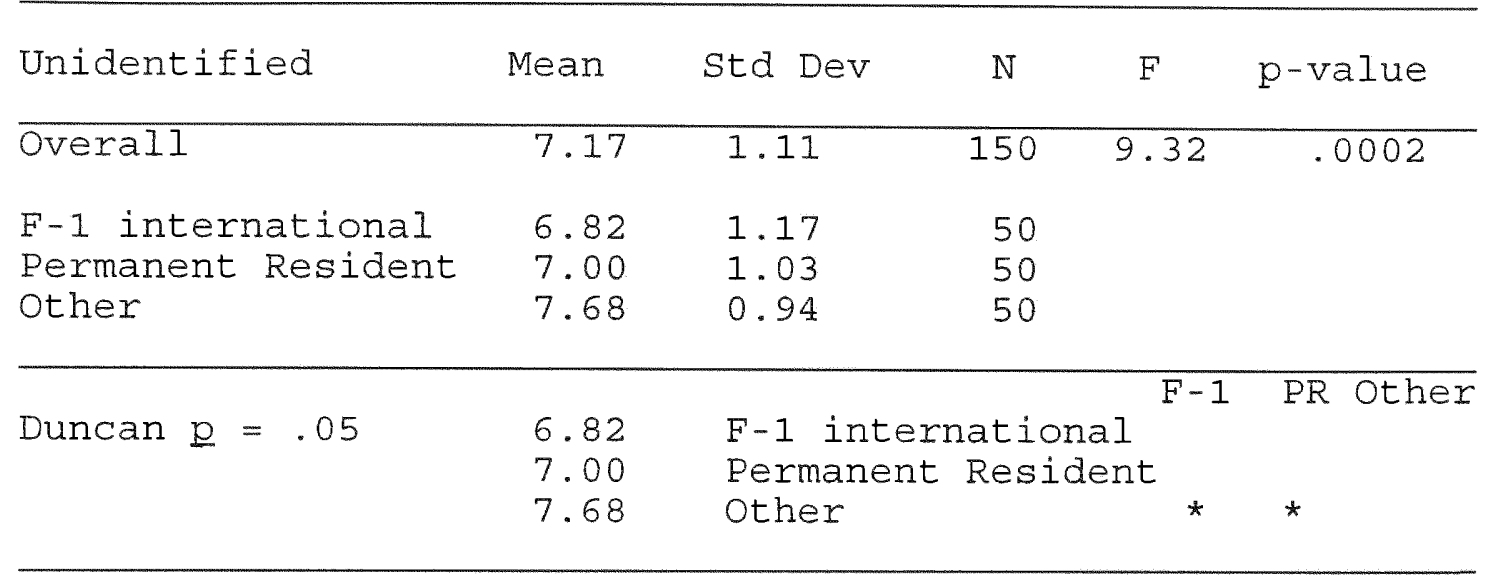

Anticipatory Behavior.

Anticipatory Behavior is the last variable measured by the questionnaire. High n-ach achievers are more active participants in activities pertaining to future events than are low achievers. A low mean score on this variable indicates a high level of anticipatory behavior as evidenced by high achievers. There is a significant difference between the means of the three sample groups as indicated by the $F$ ratio, $\underline{F}(2,147)=5.77, \underline{p}<.0039$, as shown on Table 20. The F-1 international group mean $(\underline{M}=4.70)$ was the lowest of the three groups, significantly different than the mean for the Permanent Resident group was $(\underline{M}=5.32)$ and that of the other group, $(\underline{M}=5.18)$. 
Table 20

One Way Analysis of Variance on Anticipatory Behavior Scores by Residency Status

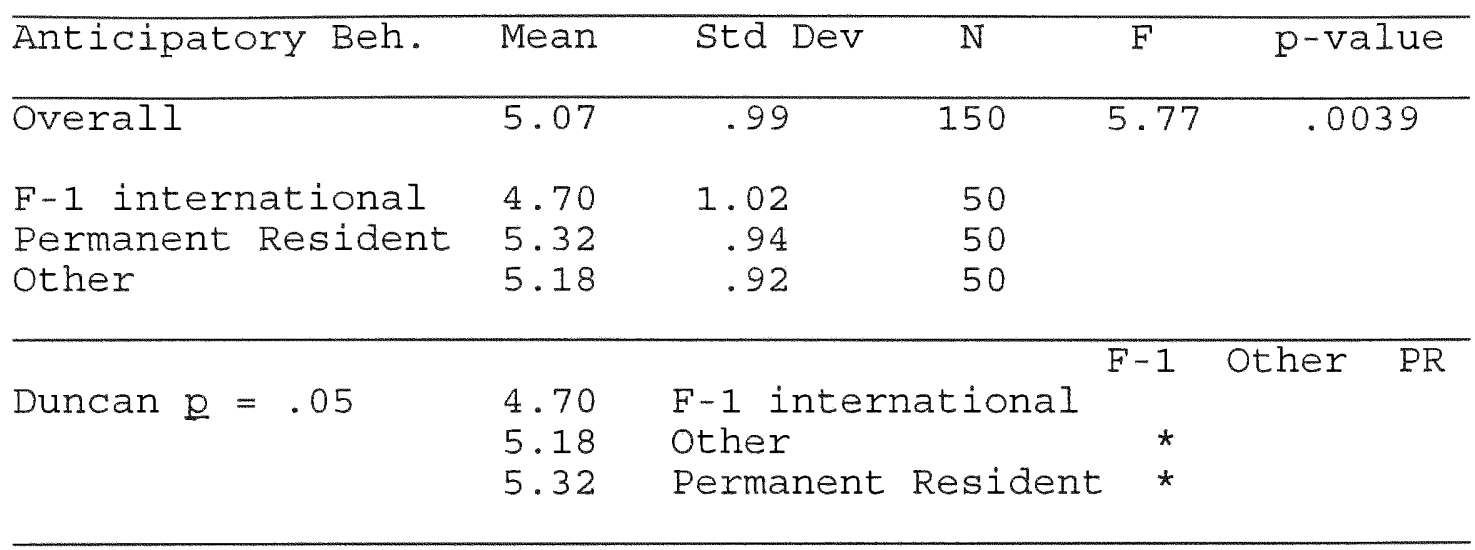

Measurement of Achievement Motivation Questionnaire Summary From the statistical analyses of the data on the Measurement of Achievement Motivation Questionnaire responses, there were six variables on which significant mean differences were found as predicted by theory. F-1 international students as postulated as high $\mathrm{n}$-ach achievers were identified by the variables of Perseverance, Parental Affection, Fear of Failure, Social Acceptance, Rigidity and Anticipatory Behavior. In addition, there were significant mean differences on four other variables, Task Orientation, Parental Restrictiveness, Competitiveness and Independence with the F-1 international students not scoring as predicted by theory for high $\mathrm{n}$-ach achievers. There was a significant difference between groups on the Unidentified 
variable but since this variable was not based on a specific achievement motivation theory, no interpretation of this result is made. There were no significant mean differences between the three groups on the four variables of Success/Failure, Future Orientation, Involvement and Testtaking (Variable 10).

Academic Success Variables

Grade Point Average

In response to the question, "Do causal attributes manifest themselves in higher academic success for F-1 international visa students?", three hypotheses were tested. Null Hypothesis 3 stated there were no significant differences in the mean Grade Point Averages among the three groups of students, F-1 international, Permanent Resident, and other. The research hypothesis not only predicted a difference between the groups' means on Grade Point Average, but also directionality with the mean Grade Point Average of F-1 international students being higher than the other 2 groups. As shown on Table 21, there was a significant $F$ ratio, $\underline{F}(2,147)=14.00, \underline{p}<.0001$. The $F-1$ international mean score $(\underline{M}=3.11)$ was significantly higher than the Permanent Resident mean score $(\underline{M}=2.49)$ and the Other group mean score $(\underline{M}=2.80)$. 
Table 21

One Way Analysis of Variance on Grade Point Averages by Residency Status

\begin{tabular}{|c|c|c|c|c|c|c|c|}
\hline Grade Point Average & Mean & std & Dev & $\mathrm{N}$ & \multicolumn{2}{|l|}{$F$} & p-value \\
\hline Overal1 & 2.80 & & .62 & 150 & \multirow{2}{*}{\multicolumn{2}{|c|}{14.26}} & .0001 \\
\hline $\begin{array}{l}\text { F-1 international } \\
\text { Permanent Resident } \\
\text { Other }\end{array}$ & $\begin{array}{l}3.11 \\
2.49 \\
2.80\end{array}$ & & $\begin{array}{l}.53 \\
.63 \\
.57\end{array}$ & $\begin{array}{l}50 \\
50 \\
50\end{array}$ & & & \\
\hline Duncan $\mathrm{p}=.05$ & $\begin{array}{l}2.49 \\
2.80 \\
3.11\end{array}$ & $\begin{array}{l}\text { Pert } \\
\text { Oth } \\
\text { F-1 }\end{array}$ & $\begin{array}{l}\text { manent } \\
\text { er } \\
\text { inter }\end{array}$ & Res & ent & $\begin{array}{l}\text { PR } \\
* \\
*\end{array}$ & $\begin{array}{l}\text { Other F-1 } \\
\star\end{array}$ \\
\hline
\end{tabular}

Number of Cumulative Credit Hours Earned

The Null Hypothesis 4 stated that there was no difference in the mean number of cumulative credits hours earned by the three sample groups. The statistical analysis of the data rejected the the null hypothesis. There was a significant $F$ ratio, $\underline{F}(2,147)=4.08, \underline{p}<.0190$, in the mean number of cumulative credit hours earned by the various groups as shown in Table 22. The Other sample's mean score $(\underline{M}=48.00)$ was the lowest among the three groups, with F-1 international $(\underline{M}=59.10)$ and Permanent Resident $(\underline{M}=61.95)$ being significantly higher. This difference may be accounted for by the greater number of semesters Permanent Resident students had in attendance at Miami-Dade Community College. 
Table 22

One Way Analysis of Variance on Cumulative Credits Earned by Residency Status

\begin{tabular}{|c|c|c|c|c|c|}
\hline Cum. Cred. Earned & Mean & Std Dev & $\mathrm{N}$ & $\mathrm{F}$ & p-value \\
\hline Overall & 56.35 & 26.33 & 150 & 4.08 & .0190 \\
\hline F-1 international & 59.10 & 21.15 & 50 & & \\
\hline Permanent Resident & 61.96 & 30.79 & 50 & & \\
\hline Other & 48.00 & 24.57 & 50 & & \\
\hline Duncan $\mathrm{p}=.05$ & $\begin{array}{l}48.00 \\
59.10 \\
61.96\end{array}$ & $\begin{array}{l}\text { Other } \\
\text { F-1 int } \\
\text { Permane }\end{array}$ & $\begin{array}{l}\text { lati } \\
\text { Res }\end{array}$ & Lt & ex $F-1$ PR \\
\hline
\end{tabular}

Number of Cumulative Credits Registered

Though not included as a dependent variable in any of the proposed hypotheses, data were collected on the number of cumulative credits registered by each subject.

Registered credits include failures in courses and courses dropped. The $F$ ratio was not significant, $\underline{E}(2,147)=2.13$, $\underline{p}>.12$, as shown in Table 23 .

Table 23

One Way Analysis of Variance on Number of Credits Reaistered by Residency status

\begin{tabular}{lccccc}
\hline No of Cred. Reg. & Mean & Std Dev & N & F & P-value \\
\hline Overall & 68.89 & 35.70 & 150 & 2.13 & .1230 \\
& & & & & \\
F-1 international & 64.04 & 23.01 & 50 & & \\
Permanent Resident & 65.32 & 38.76 & 50 & & \\
Other & 77.30 & 41.67 & 50 & & \\
& & & & & \\
\end{tabular}


Number of Changes in Majors

It was initially proposed that $F-1$ international

students would have fewer number of changes in majors than the other two research sample groups. The Null Hypothesis 5 stated there would be no significant difference in the mean number of changes in majors among the three groups of students under investigation. The statistical analysis of the data does not reject the null hypothesis. No differences were found. The $F$ ratio was $\underline{E}(2,147)=1.25, \underline{p}>.2917$ as indicated on Table 24 .

Table 24

One Way Analysis of Variance on Number of Changes in Majors by Residency Status

\begin{tabular}{lccccc}
\hline No of Changes & Mean & Std Dev & N & F & P-value \\
\hline Overall & 1.33 & .58 & 150 & 1.25 & .2917 \\
F-1 international & 1.28 & .45 & 50 & & \\
Permanent Resident & 1.28 & .54 & 50 & & \\
Other & 1.44 & .73 & 50 & & \\
\hline
\end{tabular}

Guided Biography Interview Results

Forty five guided biography interviews were conducted. Fifteen subjects randomly selected from each of the three sample groups were selected to participate in this ethnographic portion of the research study. Each student received a telephone call at home from the interviewer to arrange the appointment for the 15-20 minute interview on 
campus. Thirty nine students appeared for their session at the scheduled time. The remaining six were called again to reschedule their appointments. All forty five interviews were finally conducted by one interviewer, the researcher of the study.

The initial observation made was that the international F-1 students who had personally known the interviewer prior to the appointment were more willing to volunteer information, and, in fact, tended to expound on each question without being prodded for further information. Though the interviewer did spend a few minutes at the beginning of each session explaining the purpose of the study and allaying any concerns felt by the subject, there still appeared to be some hesitation in answering the questions or providing additional information by several subjects. Many of the Permanent Resident and other group subjects were surprised that they had been selected to participate in such a study. Some of the subjects had asked to schedule the interview during a break in their normal class schedules. Four subjects scheduled their appointment times on a Saturday and nine students selected times after 5:30pm on weekdays. A conflict with a work schedule was the main reason given by these 13 subjects who asked for different appointment arrangements.

On the average, the interview session ran 15-20 minutes in length. Even though all selected subjects had either 
completed English as a Second Language classes or had scored into college English classes, five subjects (two from the Permanent Resident group and three from the other group) had asked that the interview be conducted in Spanish. The interviewer was able to accommodate these requests in order to make the subjects more at ease with the interviewing process.

When asked the reason for selecting postsecondary educational institutions in the United states, F-1 international students responded by saying they felt degrees from the United States would better prepare them for career opportunities in their home countries or in obtaining employment positions within the United States, from both an academic and reputation perspective. There were three main reasons why these $F-1$ students had selected Miami-Dade Community college in particular: 1) because they had family living in Miami and had been told about the college from them 2) the institution was located in an area largely populated by spanish-speaking people and the familiarity of services and food to which they were accustomed and 3) the college was located in an area fairly close to their home countries for those coming from countries in central/ South America and the Caribbean.

Permanent Resident and other group subjects, in most cases, orginally arrived in Miami, coming from various Hispanic countries and then decided on making Miami their 
permanent city. It was, therefore, an easy decision for these students to attend Miami-Dade Community College since it is a very large institution with five main campuses throughout the city. In addition, campuses are easily accessible by public transportation, have various types of class schedules and methods of instruction such as weekend classes, independent study, televised classes, and bilingual classes as examples, and provides financial aid to eligible recipients. Students who were working were able to find flexibility in scheduling classes to meet their needs.

The financial consideration for attending Miami-Dade Community College is of extreme importance. Whereas F-1 international students pay $\$ 136.50$ per credit, eligible permanent residents and other non-immigrant students pay only $\$ 39.25$ per credit. In addition, F-1 international students, by the Immigration and Naturalization Services' regulations, must attend the college full-time which means taking a minimum of 12 credits per major semester. They also must have adequate resources and funds to cover living expenses, school costs and incidentals since they are not eligible to work outside of campus.

When asked about their socio-economic backgrounds, many of the F-1 students mentioned that they came from middle to upper class families in their home countries. Most of their fathers, and in many cases, their mothers as well would be considered professional people here and abroad. This was 
not the case for the Permanent Resident and other group subjects. These subjects were either the first sibling or in the first generation of children to attend college. Over $50 \%$ of the subjects in these groups came from households of blue collar workers and were themselves currently employed in blue collar type employment. Their goals, however, were to be professionals and to better their lives from that of their parents.

Corresponding to the socio-economic backgrounds of the subjects was the interest parents showed and influence they displayed in the educational lives of the subjects. As reported by the $\mathrm{F}-1$ students, their parents were very influential in helping their children select programs of study and schools to attend while growing up and were, to this date, concerned with their children's progress at Miami-Dade Community College. These students felt a strong bond of responsibility and allegiance to their families, not only for the financial support they were receiving but for the aspirations their families had for them. They did not want to "let their families down."

When asked about their parents' interest in the academic achievement of Permanent Resident and Other group subjects, most often they responded by saying their families hoped that the subjects would be able to get better jobs by going to MDCC. These subjects did not express the same concern for living up to their families' expectations as did 
the F-I international students. One reason for this lack of concern may be attributed to the factor of age. The Permanent Resident and Other group subjects were several years older than the F-1 students and away from their families for a longer period of time. They considered themselves more independent and self-sufficient than did the F-1 students who were still relying on their families and sponsors for support.

A profile of the Permanent Resident and other group subjects shows that these subjects tended to be older than the F-I international students and had attended Miami-Dade Community college on and off for a period of time. In addition, many of the Permanent Resident students and the Other immigrant students were employed and several were married with children. There were only two married F-I students in the sample.

In general, the subjects in all groups thought the educational systems in their home countries were more comprehensive and intense, teachers more demanding and the school days longer as compared to that of the United States. There were subjects in all groups who were initially shocked by the the informality of the educational system in America and specifically at Miami-Dade Community College. These subjects were not accustomed to students addressing their teachers by their first names nor by the way some students dressed for class or came prepared to class. They mentioned 
strict rules of conduct that were followed by students in their home countries and were held by faculty and family there.

Null Hypotheses Testing from the Guided Biography Interviews Corresponding to the null hypotheses testing with the instrument, Measurement of Achievement Motivation Questionnaire, four hypotheses were proposed for testing by using data from the Guided Biography Interviews. The Null Hypothesis 2 which stated there were no differences in the causal attributes for achievement motivation as posited by the sample groups was rejected. The interviewer was able to categorize the responses given by the subjects into seven major categories: effort, knowledge base, task, luck, time, independence and societal concerns. The variables of effort and knowledge base are the same internal variables found in Weiner's theory of achievement motivation as are the external variables of task and luck. The variables of time, independence and societal concerns are from the Measurement of Achievement Motivation Questionnaire.

F-1 international students expressed a strong belief in their own abilities, effort and knowledge base to succeed in their chosen careers of study at Miami-Dade Community College. The predominant sentiment was that these students were able to master any subject material if they put forth maximum effort in studying. They did not rely upon the excuse that some courses were by nature too difficult to 
master or that it was a matter of luck if they were to succeed or fail. In fact, most of the international students did not understand the concept of luck as it applied to classes or instructors. They were accustomed to accepting their classes and instructors as is and to put forth their maximum effort in succeeding.

This was not the case with Permanent Resident and Other group subjects. These subjects felt that effort and knowledge base were important factors in their achieving their academic goals, but that the type of courses and instructors they had played a very important role in their achievement level. Some subjects felt that certain subjects, especially in the areas of mathematics and science, were just too difficult for them to master and because of that factor, they were not highly motivated to put forth great effort or time in studying for these courses. In fact, they were more willing to find alternative courses than in taking these mathematics and science courses in the first place.

F-1 international students, in general, felt that they gave more time to their studying than did other students in their classes. One reason for this increase in time for studying was explained by the students' need to excel in all of their courses. The international students were quite displeased with low grades and did not like the idea of providing this information to their families back home. 
Permanent Resident and Other subjects felt that they were giving as much time as possible to their studies, but they had other priorities such as work which used up some of their time. They did realize that they may be jeopardizing their grade point averages by not studying enough or taking enough time with their school projects.

Inability to test Hypotheses 8 and 9

In the methodology section of this research study, it was proposed that two additional hypotheses, Hypotheses 8 and 9 would be tested. Hypothesis 8 stated that achievement motivation attributes differ among countries as measured by subjects' responses on the Measurement of Achievement Motivation Questionnaire and responses to the Guided Biography Interviews. However, as previously stated in the beginning of this chapter, the number of countries represented by the F-1 international students' sample subjects was over twice that of the Permanent Resident and Other group subjects. In addition to the inequity in the number of countries represented by each group in this study, the frequency counts of subjects per same country were small. In most instances, there were only one or two subjects represented by a country (Appendix D). It was, therefore, impossible to test Hypothesis 8 and to make any inferences from the available data on this question.

Hypothesis 9 was to test the differences in achievement motivation attributes by gender of subjects from the same 
countries. However, due to the same inequities found in the number of countries represented by the three sample group subjects, it was not feasible nor appropriate to test for this hypothesis. A larger pool of subjects per sample group may help eliminate these inequities and provide testing of these two hypotheses.

\section{Summary of Hypotheses Testing}

By collecting data from the college's mainframe computerized system of student data files, responses to the Measurement of Achievement Motivation Questionnaire and responses to the Guided Biography Interviews, the basic research question as to what motivates $F-1$ international students to achieve was answered.

Though reviewed and explained in depth in the following chapter, a list of the nine hypotheses considered for testing is now summarized.

The null hypothesis 1 was rejected. There were significant differences on the identified causal attributes for achievement motivation as measured by responses to the Measurement of Achievement Motivation Questionnaire.

The null hypothesis 2 was rejected. There were significant differences on the identified causal attributes for achievement motivation as measured by responses to the Guided Biography Interviews.

The null hypothesis 3 was rejected. There was a significant mean difference in Grade Point Average among the 
three sample groups, with the F-1 international group's mean being significantly higher than the other two.

The null hypothesis 4 was rejected. There was a significant mean difference in Number of Credits Earned among the three sample groups, with the Permanent Resident group's mean being higher than the other two groups' means. The null hypothesis 5 was not rejected. There were no mean differences in the number of changes in majors among the three groups under investigation.

The null hypothesis 6 was rejected. There were significant differences in the achievement motivation levels by residency classification among the three sample groups as measured by responses to the Guided Biography Interviews.

The null hypothesis 7 was rejected. There were significant differences in the maintenance of cultural identities as they affect achievement motivation among the three sample groups as measured by responses to the Guided Biography Interviews.

The null hypothesis 8 and the null hypothesis 9 were not tested as previously explained due to limited demographic variables. 
CHAPTER FIVE: SUMMARY AND CONCLUSIONS

This chapter provides a summary of the research study, theoretical framework, data collection procedures and results to the research questions under investigation. Limitations to the methodology design are explained. Suggestions for further research in the area of achievement motivation are presented.

\section{Summary}

This research study was conducted to investigate the basic research question on what motivates F-1 international students to succeed. In this study, F-1 international students have obtained permission from the federal Department of Immigration and Naturalization Services to attend a postsecondary educational institution, Miami-Dade Community College, in Miami, Florida. These students had made the decision to leave their home countries to obtain a degree from this institution and either to return home for employment upon graduating or to continue with their educational pursuits at an upper division institution.

Since it is not an easy decision for students to make in leaving home to attend an educational institution outside of their country, these students must possess certain characteristics which enable them to achieve in their new endeavors which include acclimating themselves to a dif- 
ferent environment and culture. Observations by the research investigator on the achievements of international students compared to other legal immigrant groups of students on the Wolfson Campus of Miami-Dade Community College indicated that international students tended to receive higher grades in classes, were more represented in the Honors programs and were more active in student cocurricular activities.

Since Miami-Dade Community College has such a large F-1 international student population and will continue to recruit these F-1 students to its campuses, it is important to understand the achievement motivation dynamics of this specific student body (Baldwin, 1988, 1991; Miami Herald, 1991, October 16). With the current fiscal crisis facing Miami-Dade Community College with a shortfall in funds from both the state and federal government, resources available for services to all students may be curtailed. A proposed increase in tuition may affect the number of international students able to attend the institution and increase the need for them to be successful in their classes, not repeating courses, while attending the institution.

Therefore, the basic research question arose as to why F-I international students were motivated to achieve in their educational endeavors. The main objective of this study was, in fact, to support the hypotheses that F-1 international students did out perform academically other 
immigrant groups of students and to identify the causal attributes for this achievement. It was anticipated that the results of this study could be used to improve or modify existing support services and activities for F-1 international students attending Miami-Dade Community College.

\section{Theoretical Framework}

In order to understand the results of the hypotheses testing in this study, it is necessary to present an overview of the theoretical framework used as the foundation for this research. Over the last thirty years, research studies on achievement motivation were most often either founded upon the theories of David McClelland or that of Bernard Weiner. McClelland is most frequently associated with the term Need for Achievement, $n$-ach. It was the internal motives of the individual which determined the level of achievement motivation the individual possessed. McClelland utilized the Thematic Apperception Test (TAT), a projective measurement instrument, to identify achievement motivation characteristics in subjects (McClelland, 1951, 1955) .

Weiner, who is most associated with the causal attributional theory of achievement motivation, focuses on an individual's perception and interpretation of the causes for success or failure of a task (Weiner, 1974, 1985). He identified four causes for success or failure; ability, effort, task difficulty and luck. Ability and effort are 
internal dimensions pertaining to the individual, whereas task difficulty and luck are external dimensions specific to the task, situation and time period. Subjects were asked through interviews or through the use of a test instrument to account for their perceived reasons for successes or failures at tasks.

In this research study, a combination of both major theories was incorporated as the foundation for the hypotheses testing, data collection procedures and interpretation of results. It was the belief of this investigator that the theories of McClelland and weiner individually did not provide a complete theory for studying achievement motivation, but that the combination of both theories addressed the causes and attributes of achievement motivation. Therefore, the selection of the data collection instruments and procedures were based on this combination of theories.

Data Collection Instruments and Procedures

In this study, three groups of 50 students each were randomly selected from the categories of F-1 international students, Permanent Resident students and Other students comprised of refugees, asylees and parolees. Each group consisted of 24 randomly selected males and 26 randomly selected females. The mean age of the F-1 international students was significantly younger than the mean age of the Permanent Resident and Other group subjects. In addition, 
the F-1 international student subjects came from a larger number of countries throughout the world and with greater distribution in geographical areas than did the Permanent Resident and other group subjects. Measurement of Achievement Motivation Questionnaire

Each subject completed the Measurement of Achievement Motivation Questionnaire, a 106 item instrument which measures the construct of achievement motivation among fifteen variables (Ory and Poggio, 1975). The theoretical basis of the questionnaire encompasses both McClelland's and Weiner's theories of achievement motivation. These variables are: 1) Task Orientation 2) Perseverance 3) Parental Affection 4) Fear of Failure 5) Social Acceptance 6) Success/Failure 7) Future Orientation 8) Involvement 9) Parental Restriction 10) Testtaking 11) Competitiveness 12) Independence 13) Rigidity 14) Unidentified 15) Anticipatory Behavior. The number of items per variable varied from two items being the lowest number to fourteen being the highest. The scores for the 106 items were tabulated into the fifteen variables and then analyzed using the one way Analysis of Variance (ANOVA) technique. Significant ANOVA results were further analyzed using Duncan's Post Hoc Mean Comparison procedure at the 5\% level of significance.

\section{Guided Biography Interviews}

To obtain additional information not readily available either through the college's computerized student data files 
or from the results of the Measurement of Achievement Motivation Questionnaire, 15 randomly selected subjects were chosen from each of the three groups to participate in the Guided Biography Interviews. In these Guided Biography Interviews, the interviewer asked open-ended questions pertaining to the subject's early education and cultural experiences in the home country (Levinson, 1988). Information was also collected on the subject's current academic progress at Miami-Dade Community College and the subject's perceived causes for this academic success or status.

\section{Results of Hypotheses Testing}

Research Question 1. "Do F-1 visa students differ from other foreign born students on identified causal attributes of achievement motivation for their success in college?

To investigate this research question, two hypotheses were considered. The null hypothesis 1 stated that there were no differences in the identified causal attributes for achievement motivation among the three sample groups, F-1 international students, Permanent Resident students and Other students, as measured by responses to the Measurement of Achievement Motivation Questionnaire. The null hypothesis I was rejected because there were significant mean differences on 11 of the 15 variables from the Measurement of Achievement Motivation Questionnaire.

Task orientation.

Responses to this variable indicate the type of task in 
which a subject would choose to engage. From past studies on achievement motivation, it has been shown that high $\mathrm{n}$-ach achievers tend to select moderately difficult activities and tasks in which they have a $50 \%$ chance of succeeding or failing whereas low $\mathrm{n}$-ach achievers select either very difficult or very easy tasks (McClelland, 1950, 1955; Atkinson, 1957, 1964). It was expected that F-1 international students, assumed to be high n-ach achievers, would have the lowest score on this variable which would indicate high achievement motivation. There was a significant difference among the means of the three groups; however, instead of scoring the lowest mean, the F-1 international students' mean was the highest, significantly higher than the Permanent Resident group and other group means. This result would indicate that $\mathrm{F}-1$ international students were more likely to attempt more difficult tasks with less probability of success than easier tasks. One explanation for this result may be that F-1 international students enjoy the challenge of difficult tasks as a measure of their intellectual abilities when successfully accomplishing the task and do not suffer from lower self-esteem if they fail at the task.

\section{Perseverance.}

The willingness of a subject to work extra time on a task but also the realization of the subject's limitations in ability to complete the task is measured by this vari- 
able. Low achievers give up easily and are not willing to expend additional time and effort in working on difficult problems whereas high achievers are more willing to give extra time to problems they consider solvable. They are, however, able to recognize their own limitations and to give up when the task is too difficult to complete (McClelland, 1955, 1967; Rosen, 1956: Weiner, 1985). As predicted, there was a significant mean difference between the groups with the F-1 international students' mean significantly higher than both the Permanent Resident mean and the Other group mean. For this variable, Perseverance, the higher the mean score indicates high $\mathrm{n}$-ach achievers.

\section{Parental Affection.}

As predicted, there was a significant mean difference between the three groups on this variable which measures childhood memories of parental affection. High achievers remember their parents as less warm and friendly compared to those of low achievers (Winterbottom, 1953; McClelland, 1967). The F-1 international students' mean was significantly higher than both the Permanent Resident and Other group means indicating the parents of F-1 international students were lacking in warmth and affection. One explanation for F-1 international students to be high n-ach achievers is to gain parental affection by succeeding in all tasks and endeavors. 
Fear of Failure.

This variable measures a subject's motivation for completing a task. As research shows, low achievers are more motivated by the fear of failure than by the possibility of success. The opposite is the case for high achievers who are more motivated by the possibility of success in trying a task (McClelland, 1967; Weiner, 1974, 1985). The higher a score on this variable indicates a stronger fear of failure which is associated with low achievers. A significant mean difference was found between groups with the F-1 international students' mean significantly the lowest of all the three groups.

\section{Social Acceptance.}

This variable measures the internal versus the societal need to achieve. Whereas high $\mathrm{n}$-ach achievers tend to be motivated by internal needs, they feel less pressure to conform to societal demands nor to seek external praise from others for their successes (McClelland, 1967; Weiner, 1985). As predicted, there was a significant difference between group means with the F-I international subjects' mean significantly higher than both that of Permanent Residents and others. Though F-1 internationals feel allegiance to their home countries and to their cultures, they are still motivated to achieve by internal forces specific to the individual. 


\section{Success/Failure.}

No significant difference was found between means for this variable, success/Failure. This variable identifies a subject's behavior after the successful completion of a task. High achievers tend to try more difficult problems after successfully completing a task and to take short breaks between the successful completion of a task. The reverse is the situation for low achievers (McClelland, 1955, 1967). It would appear that the subjects in all three groups tend to react the same to success when completing a task but it is not possible to identify these subjects as high or low achievers based on the mean scores of this variable.

\section{Future orientation.}

No significant mean differences were found among the three groups on this variable. It was expected that F-1 international subjects would score low on this variable which would indicate high achievers since this variable measures concern with future events. Past research has shown that low achievers are more concerned with the present and have little regard for future events (McClelland, 1955). In this study, it appears that these subjects in all three groups have concern both for their present situations and activities as well as some concern for the future as shown by the mean scores which fell within the middle of the range 
for this variable.

Involvement.

No significant mean differences were found among the three groups on this variable which measures a subject's participation level in activities. Past research studies have shown that high achievers tend to be more actively involved and have greater participation in events (McClelland, 1955). One explanation for this result may be that due to the economic and societal changes that have occurred over the past 25 years. Most individuals are now more actively involved in activities or projects than in the past when the original studies upon which this variable was based were conducted.

\section{Parental Restriction.}

This variable identifies the amount of parental restriction placed upon subjects as they were growing up. As reported in the literature, high achievers tend to see their parents as having high expectations for their children's success but not placing unnecessary restrictions upon them (Winterbottom, 1956). High achievers see their home environments as free and unrestrictive as opposed to that of low achievers. There was a significant mean difference between groups on this variable with the F-1 international subjects' mean the highest of the three groups. This score indicates that they come from more restrictive households which would not be expected from the 
review of the literature. However, there may be cultural differences and behaviors that are practiced and approved of by parents to their children in other countries which influenced the results of this variable in this direction. Testtaking.

This variable measures a subject's tendency to spend additional time on tasks. High achievers will usually spend more time on finishing a task and are many times the last person to finish an exam. There were no significant differences found between groups on this variable. One explanation for this result may be that many of the subjects still consider themselves as having language problems and automatically take extra time in trying to understand and complete problems on exams.

\section{Competitiveness.}

This variable measures a subject's need for competition. High $\mathrm{n}$-ach achievers enjoy competition against others and with the clock. They tend to work independently instead of in group activities where the success or failure of a task is left to the individual. It was predicted that F-1 international students would score as high achievers on this variable. There was a significant mean difference among groups on this variable; however, the F-1 international students' mean was the highest, which indicated they felt less competitive than others. One explanation for this unpredicted result may be the cultural orientations to 
competition that these students bring with them from their home countries which do not, in some instances, value competitiveness.

\section{Independence.}

It was expected and found that there was a signficant mean difference between groups on this variable which measures the preference for working alone or in groups. High $n$-ach achievers prefer to work alone than to work in groups which is the opposite for low n-ach achievers (McClelland, 1955, 1967). However, the F-1 international subjects, as predicted high achievers, scored the highest mean on this variable which indicated they preferred group activities more than working independently which is a characteristic of low achievers. One explanation for this unpredicted result may be that F-1 international students at Miami-Dade Community College are grouped together in honors classes and extra co-curricular activities in which they work as a unit and share the personal rewards of the group as a whole.

\section{Rigidity.}

This variable measures the tendency for flexibility and the need for adventure in working through situations. As predicted, high $\mathrm{n}$-ach achievers are more adventurous and have greater flexibility in facing problems or events. There was a significant mean difference among groups with the mean score for F-I international subjects signficantly 
the lowest, which is indicative of high achievers.

Unidentified.

This variable, comprised of three items, was not identified with any specific theory of achievement motivation. There was a significant mean difference between the groups with the F-1 international subjects' mean being the lowest. However, no interpretation of this result is provided due to the lack of achievement motivation theory as a basis for this variable.

\section{Anticipatory Behavior.}

This variable indicates a subject's interest and participation in future events. High achievers are more willing to prepare for future events than are low achievers (McClelland, 1967; Weiner, 1985). As predicted, F-1 international subjects had the lowest mean score on this variable which indicates high concern for future events, indicative of high achievers.

Hypotheses Testing Using the Guided Biography Interviews

The null hypothesis 2 stated that there were no differences in the identified causal attributes for achievement motivation among the three groups, F-I international students, Permanent Resident students and Other students, as measured by responses to the Guided Biography Interviews. The analysis of the data collected from the Guided Biography Interviews rejects this null hypothesis that there are differences in causal attributes for achievement motivation 
among the three sample groups.

The F-1 international subjects perceived their achievement motivation and academic success to be the results of effort and ability. These students expressed the need to put forth maximum effort in their academic endeavors as part of their self-esteem and self-concept as a student. Not only did their families back home expect these students to perform well in their classes, the students held the same expectations for themselves. The attributes of effort and ability are internal dimensions following Weiner's causal attributional theory of motivation (Weiner, 1974, 1985). In this regard, F-1 international students feel they have control of their own academic success based on the amount of effort the expend and their innate ability to succeed at the task at hand.

Permanent Resident and Other group subjects reported that they were not always in control of their success or failure in school. They mentioned the type of courses they had to take in order to meet a college or program requirement and the type of professor who taught the course would influence their academic success in the classroom. These attributes correspond to Weiner's task difficulty and luck dimensions. These two factors are external in nature, not under the control of the individual.

When specifically questionned about the concept of luck as influencing academic performance or success, many of the 
F-1 international students negated the importance of luck, whereas many of subjects in the Permanent Resident group and Other student group felt luck to be very important in their academic success. Additional research on the concept of luck from a cross-cultural perspective may yield interesting information which may explain the differences in causal attributes for achievement motivation between groups of foreign born students.

Research Question 2. "Do the identified causal attributes manifest themselves in higher academic success for $F-1$ international students?"

To answer this research question, three hypotheses were proposed for testing. The null hypothesis 3 stated there were no mean differences in Grade Point Average among the three groups. This null hypothesis was rejected. There was a significant mean difference in Grade Point Average among the three groups with the mean for the F-1 international group being significantly higher than the other two groups. The alternate research hypothesis predicted this directionality.

The null hypothesis 4 stated there were no mean differences in the number of credit hours earned among the three groups of students. This null hypothesis was rejected. A significant mean difference in number of credits earned was found among the three groups. However, it was expected that the F-I international subjects' mean 
would have been the highest of the three groups but this was not the case. In fact, the highest group mean for number of credits earned was that of the Permanent Resident group, significantly higher than the other group. This result may be accounted for by the greater number of semesters Permanent Resident students had, on the average, in attendance at Miami-Dade Community College.

The null hypothesis 5 stated there were no mean differences in the number of changes in majors among the three groups under investigation. The null hypothesis was not rejected. No differences were found among the three groups. This academic success variable may not be a good indicator of achievement motivation. Students are not required to inform the campus' Records department each time they change majors. The students need only to obtain a major course outline from the Advisement office and to be properly advised of the required courses needed for their new major.

Research Question 3. "Does residency classification affect a change in achievement motivation factors?"

To investigate this research question on the affect of residency classification, one null hypothesis was proposed. There would be no differences in the achievement motivation levels among the sample groups due to residency classification as measured by responses to the Guided Biography Interviews. 
Each subject selected to participate in the Guided Biography Interview was asked the question on residency classification and its effect on academic performance and motivation. International students were asked that, knowing they were to return home after completing their education programs in the United States, did this factor affect their achievement motivation to succeed. The F-1 international students most often responded to this question by mentioning the responsibility they had to succeed to the best of their abilities for their own self-concept but also for their parents' and sponsors' benefit. Upon returning to their home countries, F-1 international students expected to find good job opportunities since they had degrees from American universities. Some F-I international subjects did mention the desire to stay in the United States upon graduating and felt that they could compete with American residents for employment opportunities in the United States since they would be as qualified as other applicants.

Permanent Resident and Other group subjects responded by saying that since they had residency status, either permanent status or the possibility of permanent status, they were not as pressured to succeed in their programs of study or to complete these degrees as quickly as possible. These subjects mentioned other priorities, including current work situations, family, and economic factors which had more influence on their achievement motivation and academic 
success at Miami-Dade Community College.

Therefore, since responses to this question were different among the groups of subjects, this null hypothesis was rejected. Residency classification does affect achievement motivation factors for students.

Research question 4. "Does acculturation into the American society and its accompanying values influence academic goals?"

One null hypothesis was proposed to investigate this research question. There are no differences in the maintenance of cultural identities among the three sample groups as measured by responses to the Guided Biography Interviews. This null hypothesis was rejected based on the differences in responses among the three groups of subjects. F-1 international subjects continue to identify with their home countries, as citizens of these countries and only temporarily away from these countries. They are extremely nationalistic in their responses to questions about their identities and emphasize that they are able to adapt to living in the United States but that they have not given up their own traditional lifestyles.

Permanent Resident and other group subjects expressed varying degrees of having American identities as compared to their original country of origin identities. Responses tended to correspond to the length of time a subject had been living in the United States and if the subject had 
permanent residency status. These subjects expressed a love and admiration for their home countries, a desire to visit them but not to return to them as permanent residents again. Though not all of the subjects in the Permanent Resident group nor other student group felt completely "americanized" either by language or tradition, many commented on the advantages and possibilities afforded to them by living in the United States. These subjects recognized that they had educational opportunities here in the United States that would not have been available to them in the home countries due to either economic, political or societal circumstances. Research Question 5. "Are there cultural differences in the importance of education and the techniques for instilling such values in children?"

Two hypotheses were posited to investigate this research question. The null hypothesis 8 stated there were no differences in achievement motivation attributes among countries as measured by subjects' responses to the Measurement of Achievement Motivation Questionnaire and to the responses to the Guided Biography Interviews. The null hypothesis 9 stated there were no differences in achievement motivation attributes within a country by gender as measured by the achievement variables of Grade Point Average, responses to the Measurement of Achievement Motivation Questionnaire and responses to the Guided Biography Interviews. However, due to the varied differences in the 
demographic composition of the three groups based on country of origin and the small number of representatives from the same country, these two hypotheses were not tested. For future research, it is suggested that a larger pool of subjects per sample group may decrease the differences in demographic composition. Also, for future research it may be appropriate to focus on a specific number of subjects from designated countries and thus, eliminate the larger number of countries represented by the subjects found in the F-1 international sample.

\section{Conclusions}

The purpose of this study was to identify the causal attributes of achievement motivation possessed by F-1 international students at Miami-Dade Community College and to investigate the effects of these attributes on academic success by these students at this postsecondary institution. In order to research this inquiry, 150 randomly selected foreign born students were selected to participate in this study: 50 F-1 international visa students, 50 Permanent Resident students and 50 other students, comprised of refugees, asylees and paroles. F-1 international students are expected to return to their home countries at the completion of their studies, whereas Permanent Resident students are permitted to stay indefinitely in the United States and are eligible to apply for American citizenship and other students have been granted temporary permission to 
remain in the United states.

From the observations of this study's researcher, it appeared that international students tended to be, disproportionately to their number on campus, represented in the college's Honor classes and Honor societies in larger numbers than expected. In addition, these F-1 international students seemed to have higher Grade Point Averages in classes than did other groups of students. Therefore, this study was designed to test the hypotheses that F-1 international students did perform in fact at a higher level than did other groups of students on several academic success variables and to identify the reasons for this performance level.

Based on a combination of two theories of achievement motivation, by McClelland and Weiner, this study investigated the internal and external perceived causes for achievement motivation of the three foreign born groups of students on the Wolfson Campus of Miami-Dade Community College. Using quantitative and qualitative data collection instruments, the Measurement of Achievement Motivation Questionnaire and the Guided Biography Interview, the statistical analyses of the data indicated that F-1 international students did perform at a higher level than did the other two groups of students.

The results of this study indicate that F-1 international students possess different causal attributes for 
success than do the other two groups of subjects, Permanent Resident and other students. Previous research on high and low achievers has identified several characteristics associated with each of these two distinct achievement styles. In this study, F-I international students responded as theory had predicted on six variables of the Measurement of Achievement Motivation Questionnaire: Parental Affection, Fear of Failure, Social Acceptance, Rigidity and Anticipatory Behavior. However, the F-1 international students as high achievers did not respond as theory had predicted on four other variables, Task Orientation, Parental Restrictiveness, Competitiveness and Independence, where significant differences were found between the three groups of subjects. There were no significant differences between the three groups on the four variables of Success/Failure, Future Orientation, Involvement and Testtaking.

The information gathered from the Guided Biography Interviews support the findings of the Measurement of Achievement Motivation Questionnaire where F-1 international students identified different factors for their achievement motivation. These students identified ability and effort as the main factors which had effects on achievement motivation and, in turn, academic success. They felt that given their innate ability to learn and the necessary effort to master the subject or to perform the task, they were capable of successfully completing the activity. These internal 
attributes to achieve may manifest themselves in strong self-concepts held by F-I international students.

It should be noted that though the Permanent Resident students and the other students were enrolled in degree programs at Miami-Dade Community College, they were more often engaged in outside employment and with family responsibilities. They mentioned the importance of obtaining an education for future employment opportunities but, at the same time, they had other priorities such as work and family which required time and effort away from studying. For the F-1 international students, the priority was to succeed in school, perform well for their families back home and to obtain good jobs either in the United States or in their home countries upon the completion of their schooling. Therefore, residency status may influence achievement motivation attributes of Permanent Resident subjects and Other subjects. Residency status may not lessen or change high achieving students into low achieving students but may offer these students opportunities to direct their achievement motivation levels away from academic success in school and direct it towards work and family.

Courses on time management and decision making procedures may be of benefit to Permanent Resident and other students to enable them to maintain and apply their achievement motivation attributes to their coursework at Miami-Dade Community college and to maintain their outside interests. 
In addition, courses which include group activities and Service Learning (working on projects in the community) may keep F-1 international students highly motivated to achieve since they indicated they preferred these types of activities. Results from past research studies showed that high achievers preferred to work independently; however, the F-1 international students indicated a preference for working in groups. By providing personal development courses in conjunction with academic courses and modules within academic courses, students may find additional support to maintaining their achievement motivation and, in turn, performing at higher academic success levels.

Limitations in Methodology

In the preliminary design of the research study, the selection of the sample subjects was to be controlled on such variables as gender, age, and country of origin. Sample subjects for the Permanent Resident group and the Other group comprised of refugees, asylees and parolees were to be chosen as a match to the demographic characteristics of the F-I international student population. However, this was not possible once the computerized listing identified all possible subjects for the three sample groups: F-1 international students, Permanent Resident students and Other immigrant students. The demographics of the F-1 international students by age and country of origin were so distinctly different from the other two groups that the only 
variable which could be exactly equated in all three groups was gender. Therefore, each sample group contained 50 randomly selected subjects, 24 males and 26 females.

Twenty-seven different countries were represented by students in the F-1 international student sample. Compounding the problem of the large number of countries accounted for in this sample, there were very few countries which had more than 1 or 2 F-1 international students as selected subjects. The number of countries from which the Permanent Resident students and other immigrant students came was much smaller in both quantity and diversity. There were eleven countries for the Permanent Residents and ten countries represented by the other group students in this study. Whereas the F-1 international students came from all over the globe, from as far away as Japan and India for example, the Permanent Resident and Other subjects were predominantly from Central and South America as well as from the Caribbean. Therefore, the demographic profiles of the three groups were different and a match by the variable of country of origin was not made.

Though English proficiency was controlled by selecting students who had either completed the English as a Second Language program or who had scored into college English, large discrepancies occurred between the reading and speaking abilities and comprehension levels of the subjects in English. Several of the Permanent Resident and Other 
group subjects reported that they had difficulty understanding some of the items on the Measurement of Achievement Motivation Questionnaire. As previously reported, five subjects asked that the guided biography interviews be conducted in Spanish since they did not feel they had mastered English well enough to express their comments in the language. Therefore, there may be some errors in the answers given by subjects on the questionnaire and with the interviews due to language difficulties.

The length of time in the United States was considered an important variable on achievement motivation of subjects. To be considered as a potential subject for inclusion in this study, a student must have been living in the United States and have been attending Miami-Dade Community College for at least one year. It was assumed that F-1 international students by the end of one year in Miami would have been acclimated to their new surroundings and to the educational system at the institution. All F-1 international students had continuous enrollment at Miami-Dade Community College whereas some Permanent Resident and other group subjects had intermittent enrollment at the college. In addition, a reconsideration of the use of the testing instrument, A Measurement of Achievement Motivation Questionnaire, should be made. This instrument was designed in 1975 and administered to college students attending postsecondary institutions at that time which then formed the 
norming basis for the instrument. The characteristics of the student population now attending postsecondary institutions may be quite different from those which attended twenty years ago. Also, the appropriateness of using this instrument on various groups from different cultures should be examined.

Practical Implications and Applications

The purpose of this study was to investigate the achievement motivation of F-1 international students to succeed in their programs of study at Miami-Dade Community College and to identify the causal attributes for this achievement motivation. By identifying these attributes, comparisons can be conducted among various groups of students on the attributes for achievement motivation, as was performed in this study between F-1 international students, Permanent Resident students and Other students comprised of refugees, asylees, and parolees. In identifying and analyzing the effects of these attributes for achievement motivation, a profile of a successfully achieving student may emerge. This profile could be used in assessing the characteristics and abilities of other student groups on campus and then providing them with the necessary resources for success.

In addition, research has indicated, and is supported by this study, that high $\mathrm{n}$-ach achievers select and participate in different types of activities and tasks as 
compared to low n-ach achievers (McClelland, 1951, 1955; Atkinson, 1957; Ory \& Poggio, 1975; Weiner, 1985). It would, therefore, be advantageous to provide the appropriate types of activities to this specific student population so as to keep the achievement motivation levels high. In general, high $\mathrm{n}$-ach achievers prefer to work on tasks alone and to avoid group projects. Though this was not the case for F-I international students in this study in that they indicated that they participated and enjoyed group projects. However, when questioned about the types of group projects, these F-1 students identified projects and activities such as honors classes, Student Government, Phi Theta Kappa Honor Society and the International club. These projects and activities attract highly motivated students as members or participants and by so doing, form a very homogenous student group with similar characteristics and abilities as possessed by F-1 international students.

It may be beneficial to review the current curricula found in classes at the postsecondary level, especially at Miami-Dade Community College to see if there are varied projects and activities which support the achievement motivation needs of students. Are there challenging projects for highly motivated students? Do faculty encourage students to actively work on goal-setting activities for the future since high $\mathrm{n}$-ach achievers are future oriented in their activities? Modifications and supplementary materials 
may need to be made to the existing curricula to enrich and enhance the opportunities for F-1 international students as well as other highly motivated students in these classes. Future Research

If it is feasible, it would be interesting to follow the academic progress of this F-1 international student group as they continue with their educational studies at Miami-Dade Community College, and then to other postsecondary institutions. Do these international students maintain their high level of achievement motivation for their academic pursuits over time or do they begin to lose that need to achieve the longer they stay in the United States?

In a longitudinal study on this F-1 international student group, it would also be informative to investigate any changes in achievement motivation once the F-1 international student obtains legal residency here in the United States. Not all F-I international students will be returning to their home countries for employment. In fact, in the fields of engineering and technology, a large percentage of the current work force is comprised of foreign born graduates from American institutions (Bracey, 1991; Kirst, 1991; Smolowe, 1992; Kotkin, 1993). A pre and post test comparison could be made on the achievement motivation factors of F-1 international students when they first obtain their student visas to study here in the United States and 
later, when they obtain residency permission to stay in the United states.

Another suggestion for future research in this area of achievement motivation would be to conduct a study on the faculty's evaluations of the F-1 students as well as the other student groups to see if these students are identified as high n-ach achievers or not. It would be of interest to see if there was a match between self-identification as a high or low n-ach achieving student and that of faculty evaluations of the same students. The importance of selfesteem and self-concept as a high or low achiever could be also be explored.

Another area for future investigation on achievement motivation is that of American students choosing to study abroad in foreign countries. Do these students possess similar achievement motivation attributes for success as do F-I international students who choose to study in the United States? Do these attributes manifest themselves in similar ways such as higher Grade Point Averages in courses taken in other countries?

A replication of this study on different F-1 international student groups attending community colleges in other areas of the country would also be informative. The profile of the international students attending Miami-Dade Community College is quite different from other institutions (American Council on Education, 1990: Miami Herald, 
1991, October 16). It would, therefore, be interesting to see if the same or similar results of this study were found when studying other F-1 international students attending community colleges throughout the United States.

It was a desired outcome of this study on achievement motivation to elicit new suggestions for future investigative research in this area as it effects students, and postsecondary institutions in providing instruction and services to students. Consideration to these suggestions may lead to future research in this field and to increased knowledge on what motivates students to achieve. In this way, educational institutions can continue to serve and meet the needs of various student populations. 


\section{REFERENCES}

American Council on Education. (1990, March 12).

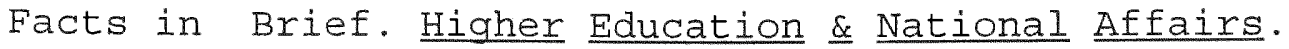
Washington, DC., p. 3 .

American Council on Education. (1991, October 21).

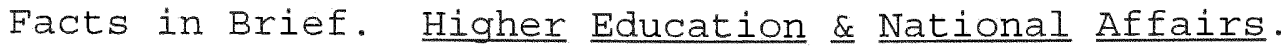
Washington, DC., p. 3.

American Council on Education. (1991, November 4). Business surpasses engineering as top subject studied by foreign students at US colleges. Higher Education $\underline{\text { E }}$ National Affairs. Washington, DC., p. 6.

Astin, A. W. (1982). Minorities in higher education. San Francisco: Jossey-Bass.

Atkinson, J. W. (1957). Motivational determinants of risk-taking behavior. Psychological Review, 64, 6 .

Atkinson, J. W. (1958). Motives in fantasy, action, and society. NY: Van Nostrand.

Atkinson, J. W. (1964). An introduction to motivation. NY: Van Nostrand.

Atkinson, J. W. \& Birch, J. (1970). The dynamics of action. NY: John Wiley.

Atkinson, J. W. \& Birch, J. (1978). Introduction to motivation. NY: Van Nostrand.

Atkinson, J. W. \& Feathers, N. T. (Eds.). (1966). A theory of achievement motivation. NY: John wiley.

Baldwin, A. (1988). International student profile 
(Report No. 88-26). Miami, FL: Miami-Dade Community College.

Baldwin, A. (1991). International student profile (Report No. 91-11R). Miami, FL: Miami-Dade Community College.

Beardsley, K. P., Stewart, G. M. \& Wilmes, M. B. Achieving styles of students and student affairs professionals. Journal of College Student Personnel, September $1987,412-419$.

Bogdan, R. \& Biklin, S. (1982). Qualitative research for education. Boston: Allyn and Bacon, Inc.

Borg, W. \& Gall, M. (1983). Educational research: an introduction. White Plains, NY: Longman, Inc.

Boyer, S. \& Sedlacek, W. (1988). Noncognitive predictors of academic success for international students, a longitudinal study. Journal of College Student Development, 29, $218-223$.

Boyer, S. \& Sedlacek, W. (1989). Noncognitive predictors of counseling center use by international students. Journal of Counseling and Development, 67, 404407.

Bracey, G. (1991, October). Why can't they be like we were? Phi Delta Kappan, 73, 104-117.

Brameld, T. (1957). Cultural foundations of education. Westport, CT: Greenwood Press.

Carter, R. \& Sedlacek, W. (1986). Needs and 
characteristics of undergraduate international students. Journal of International Student Personnel, 3, 22-24.

Cordes, C. (1984, september). School debate too often ignores effects of culture. APA Monitor, 51-54.

Cronbach, L. (1990). Essentials of psychological testing. NY: HarperCollins.

Desruisseaux, P. (1993, December 1). A foreign student record. Chronicle of Higher Education, A42.

De Palma, A. (1990, November 29). Foreigners flood U.S. graduate schools. New York Times, 1A.

Dodge, S. (1990, March 7). Culture shock and alienation remain problems for many foreign students on US campuses. Chronicle of Higher Education, A33.

Douvan, E. (1975, Spring). Higher education and feminine socialization. New Directions in Higher Education, 3, $37-50$.

Du Bois, C. (1956). Foreign students and higher education in the United States. Washington, DC: American Council on Education.

Fersh, S. \& Furlow, R. (Eds.) (1993). The commnity college and international education. Glenn Ellyn, Il: College of Dupage.

Foreign student enrollment jumps. (1991, October 16). Miami Herald, 9A.

Hall, J. (1961). Psychology of motivation. Chicago: J. B. Lippincott. 
Hilgard, E. R. (1962). Introduction to psychology. NY: Harcourt, Brace \& World, Inc.

Hodgkin, M. (1964). Cross-cultural education in anthropological perspective. Educating students from other nations. Hugh Jenkins, Ed. NY: Jossey Bass, 1983, 419435 .

Hutslar, C., Litcher, J. H. \& Knight, J. P. (1985, November). What motivates students to learn: identifying the key factors. NAASP Bulletin, 69, 94-97.

Isaac, S. \& Michael, W. (1981). Handbook in research and evaluation. San Diego: Edits Publishers.

Jenkins, H. M., (1983). Educating students from other nations. San Francisco: Jossey-Bass.

Kerlinger, F. N. (1986). Foundations of behavioral research. NY: Holt, Rinehart and Winston.

Kirst, M. (1991, October). Need to broaden our perspective concerning America's educational attainment, Phi Delta Kappan, 73, 118-120.

Kirst, M. (1993, April). Strengths and weaknesses of America. Phi Delta Kappan, 74, 613-618.

Kotkin, J. (1993, February 24). Enrolling foreign students will strengthen America's place in the global economy. Chronicle of Higher Education, B1.

Larose, S. \& Roy, R. (1991). The role of prior academic performance and non academic attributes in the prediction of the success of high-risk college students. 
Journal of College Student Development, 32, 171-177.

Lay, R. \& Wakstein, J. (1985). Race, academic achievement and self-concept of ability. Research in Higher Education, 22, 43-64.

Lee, S. (1991, May 27). Train 'em here, keep 'em here. Forbes, p. 110 .

Levine, J., Mackinnon, R. \& Reichlin, I. (1992, September 14). Why Akio and Yves beat out Johnny. Business Week, $79-80$.

Levinson, D. (1978). The seasons of a man's life. NY: Alfred A. Knopf.

Lofland, J. \& Lofland, L. (1984). A guide to qualitative observation and analysis. CA: Wadsworth Publishing Co.

Maehr, M. L. (1974). Culture and achievement motivation. American Psychologist, 29, 887-896.

Maehr, M. L. \& Braskamp, L. (1986). The motivation factor. Lexington, MA: Lexington Books.

Mangan, K. S. (19991, April 24). Community colleges scramble to meet demand for English classes for non-native speakers. Chronicle of Higher Education, A1.

Mauch, J. (1984). Foreion students: catalyst for reducing parochialism. Pittsburgh, PA: University of Pittsburgh.

McClelland, D. C. (1951). Personality. NY: Dryden Press. 
McClelland, D. C. (1955). Studies in motivation. N.Y: Appleton-Century-Crofts.

McClelland, D. C. (1967). The achieving society. NY: Free Press.

McClelland, D. C., Atkinson, J., Clark, R. \& Lowell, E. (1954). The achievement motive. NY: Appleton-CenturyCrofts.

McInerney, D. M. \& Sinclair, K. E. (1991). Cross cultural model testing: inventory of school motivation. Educational and Psychological Measurement, 51, 123-133. Miami-Dade Community College. (1991). Headlines, Miami, FL: Miami-Dade Community College.

Miami-Dade Community College. (1992). Catalog. Miami, FL: Miami-Dade Community College.

Miami-Dade Community College. (2995). Facts in brief, Miami, FL: Miami-Dade Community College.

Mohr, K. (1994, May). Making a place for foreign students in class. Education Digest, 44-48.

Moreno, V. \& Di Vesta, F. (1991). Cross cultural comparisons of study habits. Journal of Educational Psychology, 83 (2), 231-239.

Moriat, L. (1990, May 11). Foreign student influx continues: more students from E. Europe and USSR opt for degrees from US colleges and universities. Christian Science Monitor, 82, p. 8.

Murray, E. (1964). Motivation and emotion. 
Englewood, NJ: Prentice Hall.

Ory, J. \& Poggio, J. (1975). A measurement of achievement motivation. Princeton, NJ: ETS.

Portes, A. \& Wilson, K. (1976). Black white

differences in educational attainment. American

Sociological Review, 41, 414-531.

Reiter, K. (1989). High-risk students' causal

attributions for failure on a college placement test.

Unpublished doctoral disseration, Florida International

University, Miami.

Robertson, P. F. \& Vitales, R. A. (1985).

International education and the community college. Miami, FL: Miami-Dade Community College.

Roueche, J. E., Baker, G. \& Roueche, S. (1985,

Spring). Access with excellence: Toward academic success in college. Community College Review, 12, 4-9.

Rosen, B. C. (1956). The achievement syndrome: a psychocultural dimension of social stratification.

American Sociological Review, 21, 203-211.

Schuster, B., Forsterlung, F. \& Weiner, B. (1989). Perceiving the causes of success and failure. Journal of Cross Cultural Psychology, 20, 191-213.

Shigaki, I. (1983, May). Childcare practices in Japan and the United States: How do they reflect cultural values in young children? Young Children, 13-24.

Smolowe, J. (1992, April 13). The pursuit of 
excellence. Time, 139, p. 59.

Spence, J. T. (Ed.) (1983). Achievement and achievement motives: psychological and sociological approaches. San Francisco: W. H. Freeman.

Staff. (1988, December 5). Foreign students earn more than half of the US doctorates in engineering. Aviation Week $\underline{\&}$ Space Technology, p. 42.

Stipek, D. (1993). Motivation to learn. Boston: Allyn and Bacon.

Stevens, J. (1986). Applied multivariate statistics for the social sciences. Hillsdale, NJ: Lawrence Erlbaum, Associates.

Triandis, H. C. \& Brislin, R. W. (1984). Cross cultural psychology. American Psychologist, 39, 1006-1016. Wade, N. (1990, July 9). Johnny can't add, Hiroko can. New York Times, p. 16.

Weiner, B. (1974). Cognitive views of human motivation. NY: Academic Press.

Weiner, B. (1985). An attributional theory of achievement motivation and emotion. Psychological Review, 92, 548-573.

Weiner, B. (1990). History of motivational research in education. Journal of Educational Psychology, 82, 616622 .

Winer, B. J. (1962). Statistical principles in experimental design. NY: McGraw-Hill. 
Winterbottom, M. (1958). In J. W. Atkinson (Ed.), Motives in fantasy, action and society. NJ: D. Van Nostrand, $294-307$.

Zern, D. (1984). Relationships among selected childrearing variables in a cross-cultural sample of 110 societies. Developmental Psychology, 20, 683-690. 
Measurement of Achievement Motivation Questionnaire By Ory and Poggio (1975)

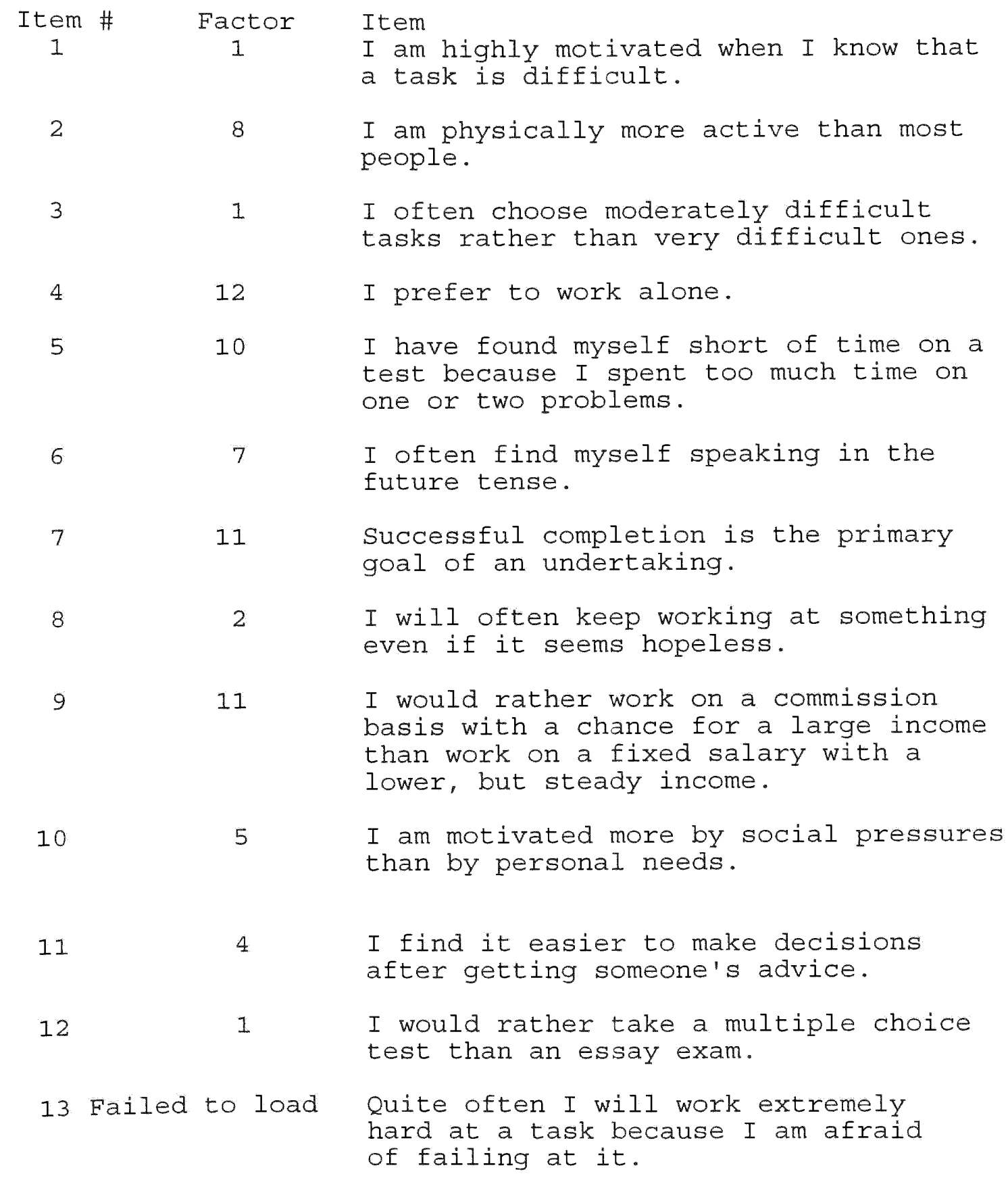


14

3

15

4

16

17

13

18

19

20

21

22

23

11

24

25

26

27

28

10
My parents (guardians) were seldom affectionate with me.

I often feel at peace with myself.

I believe that I succeed at tasks more times than I fail.

If I were a teacher, I would rather have good students, than freedom and flexibility in the job.

I would rather have the teacher set the deadines than set them myself.

My parents (guardians) seldom discouraged me from doing new things as I grew up.

I prefer games of skill to games of chance.

I view my parents' (guardians') lives as unproductive.

Getting an "A" in a course is always possible for me.

I would rather work for a company that pays well, than work for a company that pays less but affords job flexibility.

11 I can accomplish simple manual tasks faster than most people.

I feel that my parents (guardians) were very restrictive in raising me.

I become frustrated easily.

I am often the last person to finish

a test.

I am usually realistic about my goals and aspirations.
I feel that I am more likely to succeed at any given task than are most people.

I prefer to watch sports on television, 
rather than participating myself.

31 Failed to load

35

36
2
I am unhappier about doing something badly, than I am happy about doing something well.

After a considerable amount of time on a problem, I prefer to move on to an easier one.

My parents (guardians) allowed me to make my own friends.

I prefer to work on difficult projects with someone, rather than trying them alone.

I am (was) frequently the first person done with a test.

I prefer independent study programs to traditional lecture classes.

Being popular is more important than just being successful.

I am not much concerned about the present as I am about the future.

I have courage.

I have often followed my parents' (guardians') advice even when I disagreed with it.

I feel as though I can take short breaks after successfully completing one stage of a large project.

While working on a project, I often get side-tracted by new ideas.

I feel that I am being very realistic with my career choice in relation to my ability.

I like to live by the saying, "Never give up."

My parents are (were) friendly. 


\section{6}

47

48

49 Failed to load

50

51 Failed to load

52

53

54

55

56

57

58

59

60

61
2

12

3

4

2

(10ad

2

1oad

8

8

\author{
12
}

2

7

9

2
I always lacked closeness with my parents (guardians).

Often I am disappointed with my ability to interact with others.

I dislike giving up on a task.

I am motivated more by the fear of failing than by the anticipation of possible success.

I consider myself open to new ideas or beliefs.

Time is unimportant as long as I solve the problem correctly.

When the odds are against me in games of skill, I am highly motivated to do my best.

In school, I am (was) active in extracurricular activities.

I would rather change my opinion than disagree with the consensus of the group.

A true challenge is one that is practically impossible to accomplish.

It is more important to have friendly coworkers than flexibility in the job.

I enjoy(ed) classes in school with a mixture of students with varying ability.

Unfinished tasks bother me until I get a chance to finish them.

I consider myself very conscious of time.

My father (male guardian) is (was) very dominating and strict.

If I cannot solve a particular problem I would rather try an easier one than 
keep working on the harder task.

\begin{tabular}{|c|c|c|}
\hline 62 & 15 & $\begin{array}{l}\text { I will often spend days just thinking } \\
\text { and organizing before beginning the } \\
\text { work on a project. }\end{array}$ \\
\hline 63 & 7 & $\begin{array}{l}\text { I frequently find myself doing some- } \\
\text { thing now, in preparation for the } \\
\text { future. }\end{array}$ \\
\hline 64 & 4 & $\begin{array}{l}\text { Other people influence my opinions } \\
\text { more than I would like them to. }\end{array}$ \\
\hline 65 & 1 & $\begin{array}{l}\text { I enjoy completing many easy tasks } \\
\text { rather than just a few difficult ones. }\end{array}$ \\
\hline 6 & 9 & $\begin{array}{l}\text { My parents (guardians) expected a lot } \\
\text { from me when I was young. }\end{array}$ \\
\hline 67 Failed & to load & $\begin{array}{l}\text { I am a very poor gambler in games of } \\
\text { chance. }\end{array}$ \\
\hline 58 & 12 & $\begin{array}{l}\text { I seldom ask for someone's help while I } \\
\text { am working on a problem. }\end{array}$ \\
\hline 69 & 3 & $\begin{array}{l}\text { My parents (guardians) never seemed } \\
\text { very confident of their own abilities. }\end{array}$ \\
\hline 70 & 7 & $\begin{array}{l}\text { It is important to have long range } \\
\text { goals clearly in mind. }\end{array}$ \\
\hline 71 & 5 & $\begin{array}{l}\text { Monetary rewards are the best way to } \\
\text { motivate me to do my best. }\end{array}$ \\
\hline 72 & 3 & $\begin{array}{l}\text { I would often work very hard at some- } \\
\text { thing just for my parents' (guardians') } \\
\text { approval. }\end{array}$ \\
\hline 73 & 5 & $\begin{array}{l}\text { One cannot be truly successful if he/ } \\
\text { she is not also popular. }\end{array}$ \\
\hline 74 & 1 & $\begin{array}{l}\text { I will frequently make a very easy } \\
\text { task more difficult to make it more } \\
\text { interesting. }\end{array}$ \\
\hline 75 & 1 & $\begin{array}{l}\text { Certain careers are too difficult for } \\
\text { me to pursue. }\end{array}$ \\
\hline 76 & 1 & $\begin{array}{l}\text { Very difficult problems are more moti- } \\
\text { vating than moderately difficult prob- } \\
\text { lems. }\end{array}$ \\
\hline
\end{tabular}


77

78

79

80

81

82

84

85

86

87

88

89

90

91

92
Generally, I feel compelled to have the exact time.

I do not mind putting in extra hours at work if it helps me finish a task.

In school, I have usually take advantage of independent study options.

I generally aim my activities toward a goal.

I prefer a well written book to a good movie.

When younger, I felt very guilty when I disobeyed my parents.

I will work longer on problems I believe I can solve, than on those I consider close to impossible.

I will often do things for the present enjoyment and not be concerned with future consequences.

Social recognition is the primary goal of any undertaking.

Tasks are performed best through group efforts rather than through individual effort.

Games are not much fun if the competition is too strong.

It is often too much trouble to disagree with a group opinion.

Social acceptance is more important than personal success.

I would rather fail at a difficult task than succeed at an almost effortless task.

I will often do my best in order to avoid the embarassment of failure.

I enjoy competing against the clock. 
After participating in athletics, I find it much easier to accept defeat if I have played well.

My parents (guardians) rewarded me with a hug or a similar show of affection for doing something well.

I often pack my suitcase days before I am ready to leave.

Success encourages me to attempt even more difficult problems.

I feel that I can succeed at almost anything I try.

I enjoy being in groups with people of equal ability.

I would rather be unpopular with my own opinions than be popular with someone else's opinions.

It is important to finish something once it is started.

I enjoy trying to solve problems some people would consider impossible.

After successfully completing a task, I like to relax for a short period before attempting something new.

I consider myself an independent thinker.

My parents (guardians) gave me considerable independence early in life.

I will often attempt a difficult problem after failing at an easier one.

I realize the limits of my own ability and knowledge. 
1. Task Orientation $-1,3,12,22,65,74,75,76,79,81$, $90,97,101,105$

2. Perseverance $-8,44,48,50,58,61,96,100$

3. Parental Affection - 14, 19, 21, 40, 45, 46, 69, 72, 82, 94

4. Fear of Failure - 11, 15, 16, 26, 28, 39, 43, 47, 64, 103

5. Social Acceptance - 10, 37, 71, 73, 78, 85, 88, 89, 99

6. Success/Failure - 32, 41, 83, 91, 98, 102, 106

7. Future Orientation $-6,38,59,63,70,77,80$

8. Involvement $-2,20,29,30,52,53,93$

9. Parental Restriction $-25,33,60,66,104$

10. Testtaking $-5,27,35$

11. Competitiveness $-7,9,23,24,87,92$

12. Independence - 4, 34, 57, 68, 86

13. Rigidity $-17,18,54,55,56$

14. Unidentified - 36, 42,84

15. Anticipatory Behavior - 62, 95 


\section{APPENDIX B \\ Guided Biography Interview}

Introduction

Thank you for agreeing to participate in this study. I appreciate your cooperation, time and effort in helping me conduct this research. Basically, I will be asking you to recall your personal experiences and knowledge of the educational system of your home country and with your present status at Miami-Dade Community College. There are no right or wrong responses, so please feel free to respond as you would like. Again, I want to assure you that there will be complete confidentiality of this material. Do you have any questions you would like for me to answer?

Please tell me why you are pursuing a college degree in the United states. (Probe-Not possible in home country?)

Why have you decided on attending MDCC? 
Besides for the educational reasons, are there any other reasons for coming to the United States and to Miami, specifically?

Do you feel that your reasons for attending college have been influenced by anyone specific such as a family member or teacher? of so, who and in what ways?

Have other members of your family attended college? (ProbeDid they influence your decision to study?)

Realizing that many of our students at MDCC have had their early educational experiences in countries other than the United States, please tell me about your educational history. 
Comparing your home country's focus on education and that of the United States, are there any similarities or diferences between the two? What are they?

Many factors may effect your academic success at MDCC. How do you see yourself academically compared to other MDCC students?

What factors are effecting your progress at the college? (Luck, ability, effort, task)

Are there things which you would like to see changed, either in yourself or at MDCC to help you reach your full academic potential if you think you haven't as yet? 
Do you think that knowing that you (will return to your home country after completing your education here), (have permanent residency here in the United states) or (are eligible to obtain residency here in the United states) has an effect on your achievement at MDCC? If so, in what ways?

Would it make a difference, either positive or negative on your educational achievements and career path if the opposite situation were the case? (See above choices)

Have there been any changes in how you view your educational goals since you arrived in the United states? If so, what are they? (Probe-Any other changes, attitudes, beliefs, etc?) 
Are there any other areas or additional information you would like to discuss?

Again, thank you for participating in this research study. Your information has been extremely helpful. I truly appreciate your time, effort and cooperation in this endeavor. 
APPENDIX C

Distribution of Countries by Residency status

Residency status

Country

F-1 Int' 1 Per Res Other

count Pct count Pct count Pct

\begin{tabular}{|c|c|c|c|c|c|c|}
\hline Argentina (Ar) & 2 & 4.0 & 0 & 0.0 & 0 & 0.0 \\
\hline Brazil (Br) & 0 & 0.0 & 1 & 2.0 & 2 & 4.0 \\
\hline China (Ch) & 1 & 2.0 & 0 & 0.0 & 0 & 0.0 \\
\hline Chile (Ci). & 1 & 2.0 & 0 & 0.0 & 0 & 0.0 \\
\hline Colombia (Co) & 5 & 10.0 & 15 & 30.0 & 10 & 20.0 \\
\hline Costa Rica (Cs) & 1 & 2.0 & 0 & 0.0 & 0 & 0.0 \\
\hline Cuba (Cu) & 0 & 0.0 & 0 & 0.0 & 7 & 14.0 \\
\hline $\begin{array}{l}\text { Dominican } \\
\text { Republic (DR) }\end{array}$ & 2 & 4.0 & 3 & 6.0 & 0 & 0.0 \\
\hline Ecuador (EC) & 2 & 4.0 & 2 & 4.0 & 0 & 0.0 \\
\hline France (Fr) & 1 & 2.0 & 0 & 0.0 & 0 & 0.0 \\
\hline Haiti ( $\mathrm{Ha})$ & 3 & 6.0 & 0 & 0.0 & 1 & 2.0 \\
\hline Hungary (Hu) & 1 & 2.0 & 0 & 0.0 & 0 & 0.0 \\
\hline India (In) & 2 & 4.0 & 0 & 0.0 & 0 & 0.0 \\
\hline
\end{tabular}


Residency status

(table continues)

Country

Israel (Is)

Italy (It)

Japan (Ja)

Jamaica (Jm)

Lebanon (Le)

Mexico (Mx)

Nicaragua (Na)

Netherlands

Peru (Pe)

Panama (Pn)

Spain (Sp)

Sudan (Su)

Sweden (Sw)

Trinidad (Tr)

Uruguay (Ur)$$
\overline{-}
$$

F-1 Int'I

Count PCt

Per Res

count Pct Count PCt

6.0

1

2.0

0

0.0

2

4.0

2

4. 0

0

0.0

24.0

0

0.0

0

0.0

36.0

$6 \quad 12.0$

0

0.0

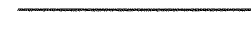

2.0

0

0.0

0

0.0

$\longrightarrow$

4. 0

2

4. 0

-

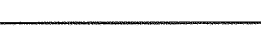

0

$\begin{array}{lllll}0.0 & 0 & 0.0 & 9 & 18.0\end{array}$

(Ne)

12.0

0

0.0

0

0.0

$\longrightarrow$

3

$3-6.0$

12.0

12

24.0

(n)


(table continues)

\section{Residency Status}

Country

F-1 Int'1 Per Res Other

Count Pet Count Pet Count Pet

Venezuela (Ve)

24.0

$8 \quad 16.0$

12.0

Total

$\begin{array}{llllll}50 & 100.0 & 50 & 100.0 & 50 & 100.0\end{array}$

